\title{
The South Atlantic Anticyclone as a key player for the representation of the tropical Atlantic climate in coupled climate models
}

\author{
William Cabos ${ }^{1}$ (D) Dmitry V. Sein ${ }^{2,3} \cdot$ Joaquim G. Pinto $^{4,5} \cdot$ Andreas H. Fink $^{6}$ • \\ Nikolay V. Koldunov ${ }^{7}$. Francisco Alvarez $^{1} \cdot$ Alfredo Izquierdo $^{8} \cdot$ Noel Keenlyside $^{9}$. \\ Daniela $\mathrm{Jacob}^{7}$
}

Received: 31 January 2016 / Accepted: 10 August 2016 / Published online: 19 August 2016

(C) The Author(s) 2016. This article is published with open access at Springerlink.com

\begin{abstract}
The key role of the South Atlantic Anticyclone (SAA) on the seasonal cycle of the tropical Atlantic is investigated with a regionally coupled atmosphere-ocean model for two different coupled domains. Both domains include the equatorial Atlantic and a large portion of the northern tropical Atlantic, but one extends southward, and the other northwestward. The SAA is simulated as internal model variability in the former, and is prescribed as external forcing in the latter. In the first case, the model shows significant warm biases in sea surface temperature (SST) in the Angola-Benguela front zone. If the SAA is externally prescribed, these biases are substantially reduced. The biases are both of oceanic and atmospheric origin, and are
\end{abstract}

William Cabos

william.cabos@uah.es

1 Department of Physics, University of Alcalá, Alcalá de Henares, Madrid, Spain

2 Alfred Wegener Institute for Polar and Marine Research, Bremerhaven, Germany

3 P. P. Shirshov Institute of Oceanology RAS, St.Petersburg, Russia

4 Department of Meteorology, University of Reading, Reading, UK

5 Institute for Geophysics and Meteorology, University of Cologne, Cologne, Germany

6 Institute of Meteorology and Climate Research, Karlsruhe Institute of Technology, Karlsruhe, Germany

7 Climate Service Center, Helmholtz Zentrum Geesthacht, Hamburg, Germany

8 Marine Science and Technological Center of Andalusia, University of Cadiz, Cádiz, Spain

9 Geophysical Institute and Bjerknes Centre for Climate Research, University of Bergen, Bergen, Norway influenced by ocean-atmosphere interactions in coupled runs. The strong SST austral summer biases are associated with a weaker SAA, which weakens the winds over the southeastern tropical Atlantic, deepens the thermocline and prevents the local coastal upwelling of colder water. The biases in the basins interior in this season could be related to the advection and eddy transport of the coastal warm anomalies. In winter, the deeper thermocline and atmospheric fluxes are probably the main biases sources. Biases in incoming solar radiation and thus cloudiness seem to be a secondary effect only observed in austral winter. We conclude that the external prescription of the SAA south of $20^{\circ} \mathrm{S}$ improves the simulation of the seasonal cycle over the tropical Atlantic, revealing the fundamental role of this anticyclone in shaping the climate over this region.

Keywords South Atlantic Anticyclone - Southeastern tropical Atlantic $\cdot$ Seasonal cycle $\cdot$ SST biases

\section{Introduction}

The tropical oceans are one of the key areas of weather and climate variability. Coupled atmosphere-ocean general circulation models (AOGCMs) typically show warm biases in sea surface temperature (SST) over both the tropical Pacific and Atlantic oceans, particularly in their eastern parts (Mechoso et al. 1995). Richter et al. (2012b) reported that the tropical Atlantic biases persist in most AOGCMs participating in the Coupled Model Intercomparison Project (CMIP) Phase 3 and 5 (Meehl et al. 2007; Taylor et al. 2012). Several studies have explored the causes and structure of these biases: for example, Li and Xie (2012) suggested that the biases could be both of oceanic or atmospheric origin. They proposed the existence of two 
predominant types of tropical-wide errors in CMIP models. The first can be traced back to biases in atmospheric simulation of cloud cover and shows a broad meridional structure of the same sign across all basins, with models with enhanced cloud cover featuring lower biases in tropical-wide SST. The second originates from differences in the simulation of the thermocline depth, with models with a deeper thermocline typically showing a warmer equatorial cold tongue. Over the tropical Atlantic, the oceanic and atmospheric processes are strongly coupled and this coupling is a major determinant of climate variability over the adjacent tropical continents. For example, the year-toyear variability of the seasonal development of Atlantic cold tongue has strong impacts on rainfall variability over West Africa in general, particularly on the onset of the West African monsoon (Kushnir et al. 2006; Brandt et al. 2011). Thus, the warm SST biases in coupled models severely inhibits the ability of these models to correctly reproduce both the observed SST variability in the equatorial Atlantic and the dynamics governing that variability (Ding et al. 2015).

The present paper focuses on the southeastern tropical Atlantic (SETA; Fig. 1a). Various mechanisms have been proposed for the development of warm biases in this region. Some of the mechanisms are related and can be linked to a specific season. A possible cause involves the models' inability to correctly simulate the wind stress in the SETA. Colberg and Reason (2006) demonstrate the sensitivity of the Angola Benguela Frontal Zone position to the wind stress forcing as its curl controls the southeastward flow of the South Equatorial Counter Current towards the Angolan coast, and the opposing northward flow of cold water is mainly the result of geostrophic adjustment to coastal upwelling driven by the meridional wind stress. These local wind stress inaccuracies can be related to the large-scale atmospheric circulation due to the incorrect simulation of the strength of the South Atlantic Anticyclone (SAA, e.g., Lübbecke et al. 2010). Another possible source of errors arises from a poor simulation of convection over the continents adjacent to the tropical Atlantic during boreal spring: a deficient (excessive) precipitation over tropical South America (Africa) could cause an anomalous zonal sea-level pressure gradient in the equatorial Atlantic that produces weaker easterlies in the southern hemispheric tropical Atlantic Ocean. This bias is present in atmospheric GCMs (AGCM) forced by observed SST (Richter and Xie 2008; Wahl et al. 2011).

The models' excessive radiative forcing due to errors in reproducing the observed low, marine stratus cloud cover over the southeastern ocean can also lead to an anomalous warming (Tanimoto and Xie 2002; Huang et al. 2007). Other possible mechanisms that lead to the generation of warm biases in the SETA are the modification of the

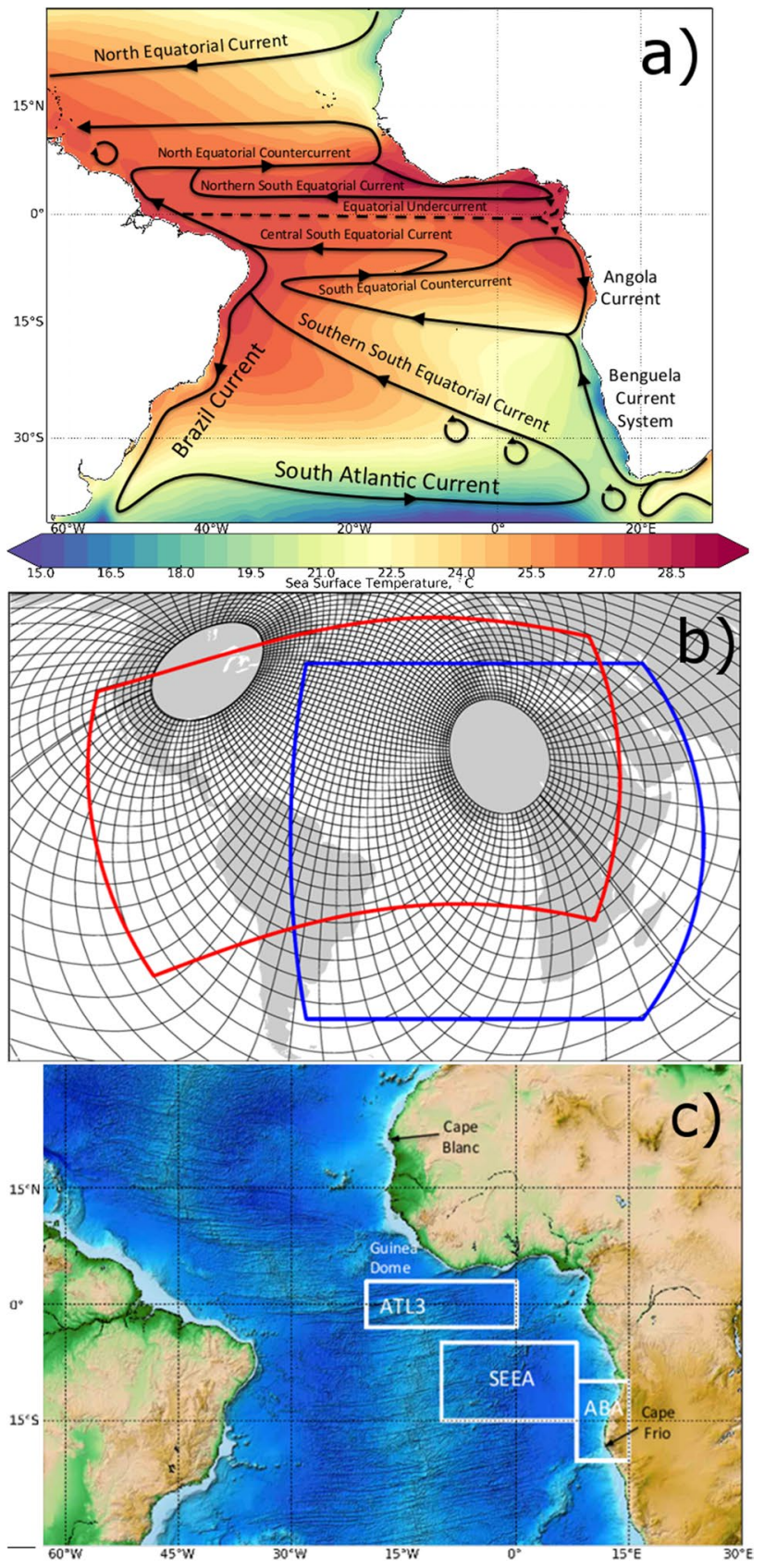

Fig. 1 a Upper ocean currents in the tropical Atlantic. b MPI-OM TR04 setup (black lines). REMO-AFR setup (blue line) and REMONAT setup (red line). Every 12 nth ocean grid line is shown. c Regions used for the definition of the different indices and geographical points mentioned in the text

upper-ocean stratification and barrier layers by incorrectly simulated rainfall (e.g., Liu et al. 2009) and the ocean GCMs (OGCM) inability to correctly simulate the sharp thermocline characteristic of the equatorial and southeastern tropical Atlantic (Xu et al. 2014; Richter 2015). Additionally, an inadequate simulation of the seasonal shifts of the intertropical convergence zone (ITCZ) in timing and 
location contributes to errors in the modeled wind stress and low marine clouds.

As mentioned-above, the variability of the South Atlantic Anticyclone (SAA) affects the southern tropical Atlantic through the wind stress variability in the region, which plays a leading role in the generation of SST anomalies in the SETA (e.g., Lübbecke et al. 2010). The seasonal cycle of the SAA is mainly controlled by the convective heat sources over South America and southern Africa, and by the interaction of orography with the trade easterlies and the midlatitude westerlies (Rodwell and Hoskins 2001; Miyasaka and Nakamura 2010). It is also influenced by remote, cross-hemispheric effects of heat sources located in the Northern Hemisphere ( $\mathrm{Ji}$ et al. 2014). These fundamental mechanisms lead to a notably stronger SAA in austral winter than during austral summer. In the latter season, the SAA is mainly a response to heating over the adjacent Southern Hemisphere continental land masses, while the northern hemispheric heat sources are responsible for the strengthening of the anticyclone in austral winter (Richter et al. 2008; Lee et al. 2013; Ji et al. 2014).

According to Seager et al. (2003), air-sea interactions could provide a stronger contribution to the SAA development during the austral summer. The authors propose a positive feedback mechanism for this season, in which a strengthening of the SAA is associated with decreased SST in the east and with warmer conditions in the west due to poleward advection of warmer air in the lower troposphere, thereby enhancing the subtropical zonal SST gradient. The strengthened SST gradient reinforces in turn the anticyclonic circulation by stabilizing the atmosphere in the east and making it more unstable and susceptible to deep convection in the west. Under such conditions, ocean upwelling and advection drive the seasonal cycle of the SST asymmetry and control the strengthening of the SAA without greatly influencing their seasonal cycle. However, based on experiments with an uncoupled AGCM, Richter et al. (2008) found that the regional zonal gradients of SST have only a minor impact on the SAA, probably due to the absence of air-sea interactions in their uncoupled model. Another factor that could influence this result is that their analysis focuses on the austral winter season, when the strength of the SAA is mostly determined by monsoonal heating in the northern hemisphere (Lee et al. 2013). Finally, Miyasaka and Nakamura (2010) proposed an additional mechanism, in which cool and warm anomalies over ocean and land surfaces, respectively act as sources of anticyclonic and cyclonic potential vorticity, creating along shore wind anomalies towards the equator.

The influence of horizontal resolution has also been explored with a limited area model. Seo et al. (2006) showed that resolution could play a role in the generation of SETA biases, while Patricola et al. (2012) suggested that simply increasing spatial resolution does not fully remove the biases. Moreover, Doi et al. (2012) concluded that greater resolution does not suffice to reduce the warm SST biases in global models. On the other hand, Harlaß et al. (2015) recently provided evidence that higher horizontal resolution accompanied by an enhanced vertical resolution does substantially improve the simulation of TA SST, precipitation and the representation of the upper ocean thermal structure, especially at the equator. In recent years, the use of regional coupled atmosphere ocean models has increased, as they enable a more detailed analysis of regional climate conditions and variability (e.g., Döscher et al. 2002; Mikolajewicz et al. 2005; Ratnam et al. 2008; Sein et al. 2014). Additionally to the higher horizontal and vertical resolution, regional climate models imply a sharper focus on selected domain location (Sein et al. 2015). The freedom of choice regarding the domain allows not only simulating the coupled interactions between components of the climate system, but also to either include or exclude some of the key sources of variability for the region of interest. This feature is particularly useful for studies in regions where complex feedbacks between the various components of the regional and global climate system occur (e.g., Sein et al. 2014)—like the SETA study region.

In the present paper, the high-resolution regionally coupled atmosphere ocean model ROM (Sein et al. 2015) is used to assess (1) the impact of the SAA location and strength on the simulation of the southern tropical Atlantic climate and (2) the role of atmosphere-ocean coupling in its seasonal cycle. The model encompasses a region where a limited area atmospheric model is coupled to a global ocean with uncoupled ocean dynamics outside the coupled region. This allows for a better understanding of local versus remote forcings of the SAA and to better resolve low-level cloud and deep convective dynamics, as well as air-sea interactions.

Our strategy is based on the comparison of ROM simulations that differ by the coupled domain placement. In the first setup, the coupled model domain includes all atmospheric features relevant for the regional southern tropical Atlantic dynamics, namely the ITCZ and the SAA. In the second setup, the coupled domain is shifted towards the Northern Hemisphere to explicitly exclude the core and southern part of the SAA. With this experimental design, the role of the SAA as an internal versus external forcing is assessed, as well as the importance of a correct simulation of SAA for the southern tropical Atlantic climate. Additional stand-alone simulations with the ocean and atmospheric components of our regional coupled model provide further insight on the impact of ocean-atmosphere interaction processes for the simulated SAA and SST. The models and experiments are briefly described in Sect. 2 and the results are discussed in Sects. 3-6. Finally, our conclusions are given in Sect. 7. 


\section{Experimental design}

The regionally coupled model ROM (Sein et al. 2015) consists of a global ocean-sea ice model (MPIOM) coupled to an atmospheric regional model (REMO) and global terrestrial hydrology model (HD). The global ocean is divided into a coupled subdomain, where the ocean and the atmosphere interact, and an uncoupled region where the ocean model is driven by prescribed "perfect" atmospheric forcing and runs without any feedbacks. This allows including or excluding regions that potentially act as sources of forcing for the southern tropical Atlantic from the area of active coupling. Moreover, it permits to explore the impact of model resolution in a computationally affordable way. The coupling interval between the ocean and the atmosphere is $3 \mathrm{~h}$. Lateral atmospheric and upper oceanic boundary conditions outside the coupled domain were prescribed using ERA40 reanalysis (Uppala et al. 2005) data. Following the Davies relaxation scheme (Davies 1983), no nudging is applied outside the eight points used as boundary conditions. The simulation period is 1958-2001. The MPIOM configuration used for all experiments features the grid poles over North America and Northeastern Africa (Fig. 1b). The horizontal resolution reaches $5 \mathrm{~km}$ in the north tropical Atlantic and gradually diminishes to $100 \mathrm{~km}$ in the southern oceans. The model has 40 vertical levels, with increasing level thickness towards the ocean bottom.

To discern the impact of the SAA on the simulation of the seasonal cycle in the tropical Atlantic, we use two different REMO domains with constant grid spacing in rotated grids (Fig. 1b). Both domains include the southern tropical Atlantic. The AFR domain has $50 \mathrm{~km}$ resolution and covers the whole SAA region and includes Africa, parts of the Indian Ocean, and the Mediterranean region. The NAT domain has also $50 \mathrm{~km}$ resolution and only includes the northern part of the SAA, but extends to the North Atlantic, the eastern tropical Pacific, and the Mediterranean Sea regions.

The impact of coupling on the atmosphere and ocean is explored with the help of additional uncoupled runs for MPIOM and AFR REMO configurations. The MPIOM standalone ocean simulation (hereafter TR04) is forced with ERA40 Reanalysis data. The list of experiments analyzed here is summarized in Table 1 . The sensitivity of the model results to changes in resolution and the parameterization of large-scale precipitation has also been explored. As the results of these sensitivity experiments do not change our main conclusions, we do not show them here in detail. However, we refer to the results of these simulations where it is relevant for the discussion.

The outcome of our simulations is compared in the paper against different observational products. Mean sea level pressure (MSLP) and 10-m winds are taken from the
Table 1 summarizes and labels each one of the NAT and AFR experiments, according to horizontal resolution, precipitation parameterization and whether it is coupled or not

\begin{tabular}{lll}
\hline Exp. no. & Atmosheric horiz.res $(\mathrm{km})$ & Description \\
\hline AFR50C & 50 & Coupled \\
NAT50C & 50 & Coupled \\
AFR50U & 50 & Atmospheric uncoupled \\
TR04 & & Oceanic uncoupled \\
\hline
\end{tabular}

ERA40 reanalysis. Higher resolution $(25 \mathrm{~km})$ wind data over the ocean from the National Aeronautics and Space Agency's (NASA) Quick Scatterometer (QuikSCAT) satellite are also considered. As an observational reference for the SST, we resort to the National Oceanic and Atmospheric Administration's (NOAA) Optimum Interpolation SST V2 dataset (OISSTV2; Reynolds et al. 2007), and also to the Global Ocean Data Assimilation System (GODAS; Behringer and Xue 2004) from the National Centers for Environmental prediction (NCEP). The latter SST data are considered in conjunction with winds from the NCEP reanalysis (Kalnay et al. 1996). Sub-surface ocean temperature (for the computation of thermocline depth) is taken from the Polar Science Center Hydrographic Climatology (PHC 3.0; Steele et al. 2001). Information on Sea Surface Height is retrieved from the NCEP Climate Forecasting System Reanalysis (CFSR, Saha et al. 2010) and, finally, incoming solar radiation at the Earth's surface data used here belong to the Surface Solar Radiation Dataset-Heliosat (SARAH; Müller et al. 2015), from the Satellite Application Facility on Climate Monitoring (CM SAF) consortium.

\section{General features of the circulation in the southern tropical Atlantic}

The general characteristics of the circulation in the southern tropical Atlantic are analyzed as represented by the different experiments (Table 1). The DJF mean sea level pressure (MSLP) for the period 1980-1999 is depicted in Fig. 2 for ERA40, together with the corresponding biases of AFR coupled and uncoupled simulations, as well as NAT coupled simulations. The AFR domains simulate an austral summer SAA with its northern, westward flowing branch systematically weakened compared to both ERA40 and the NAT domain. This leads to a cyclonic anomaly centered east of the southern tropical Atlantic, which weakens the equatorward winds in the SETA region (see Fig. 1c). This feature of the coupled AFR simulation does not depend on the parameterizations used (not shown) and is particularly clear when the AFR (Fig. 2b, d) and NAT domains (Fig. 2c) are compared. The weaker MSLP values for the simulated 
Fig. 2 DJF MSLP for 19801999. a ERA 40 climatology. The remaining figures show the DJF difference of simulated MSLP with ERA40 for coupled simulations: b AFR50U, c NAT50C and d AFR50C. Pressure is given in Pascal. Note that the NAT domain extends roughly to $15 \mathrm{~S}$
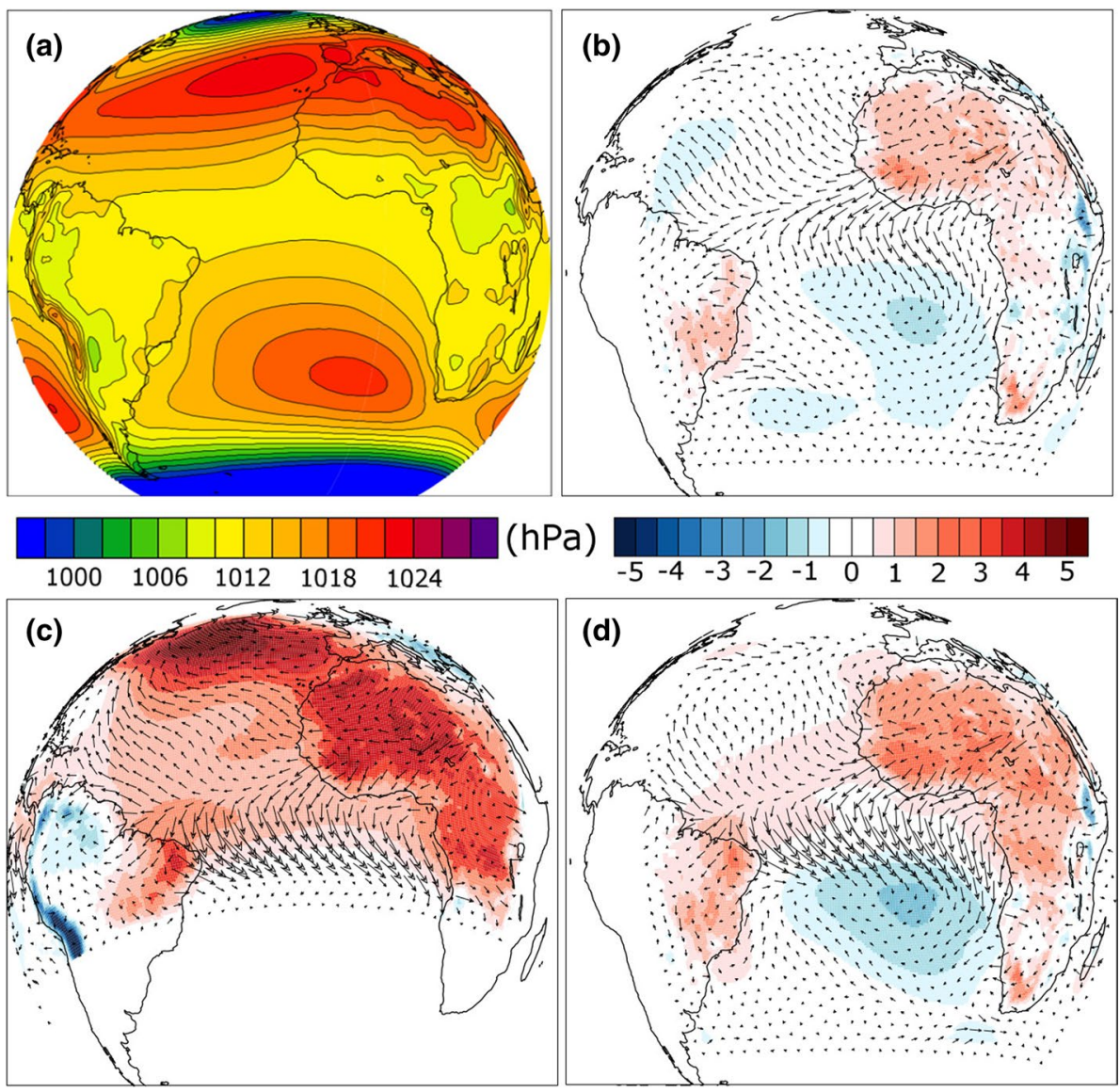

SAA are associated with stronger biases in the SSTs for the AFR domain compared to NAT (Fig. 3c, d). These SST biases are generally higher in both of the coupled simulations than in the standalone TR04 run, but there is quite some similarity in structure. The small negative biases in the equatorial strip, already present in TR04 simulation, become stronger with the coupling in both setups, especially in the eastern and western parts of the domain. On the other hand, the strengthening of the cold bias north of the equator in the region of stronger variability (box Atl3 in Fig. 1c) is compensated by a warmer SST south of the equator, reducing the mean bias here.

While the structure of the equatorial biases is not similar to those that are characteristic of global coupled models (see e.g., Li and Xie 2012), it does correspond to a weakening of the zonal SST gradient. The biases become more positive (negative) south (north) of the equatorial line. The SST biases in the Benguela Upwelling System in the AFR simulation corresponds to the typical bias pattern often found in AOGCMs (e.g., Richter et al. 2012a). This simulation shows the strongest warm bias along the coast of southern Africa near the Angola Benguela Front Zone, and along the Benguela Upwelling System expanding through the SETA. In the NAT domain, the SST bias in DJF is significantly reduced, as illustrated in the corresponding panel of Fig. 3. Our sensitivity studies with different atmospheric and ocean parameterizations indicate that although SETA SST bias can change, its large-scale pattern is rather robust and can be related to the errors in the simulation of the SAA (not shown).

The coupling also affects the precipitation patterns (Fig. 4). The uncoupled REMO simulation shows positive precipitation biases both east and west along the equator, off the coasts of Brazil and Africa, extending southward to around $10^{\circ} \mathrm{S}$, while negative biases are mainly located in the Gulf of Guinea north of the equator. In the coupled simulations, air-sea interactions cause anomalous convergence south of the equator and divergence at the equator and to the north (not shown). The precipitation bias is associated with northerly wind anomalies and cold SST biases at the equator and warm anomalies to the south. This suggests that a mechanism similar to the Wind-Evaporation-SST feedback like the one operating in the meridional mode may act (cf. Richter and Xie 2008). Consistently, the ITCZ is effectively displaced southward, or more precisely, a "double ITCZ" is created. While the magnitude and details of this effect depend on the set-up of the coupled model, this erroneous pattern is present in all coupled simulations.

The differences in simulated MSLP are smaller in austral winter (Fig. 5), when the SAA, together with the North 
Fig. 3 DJF SST for the 1980-1999 period. a The Reynolds OISST V2climatology. The remaining figures show the difference of simulated DJF SST climatology with OISST V2 for b TR04, c NAT50C and d AFR50C
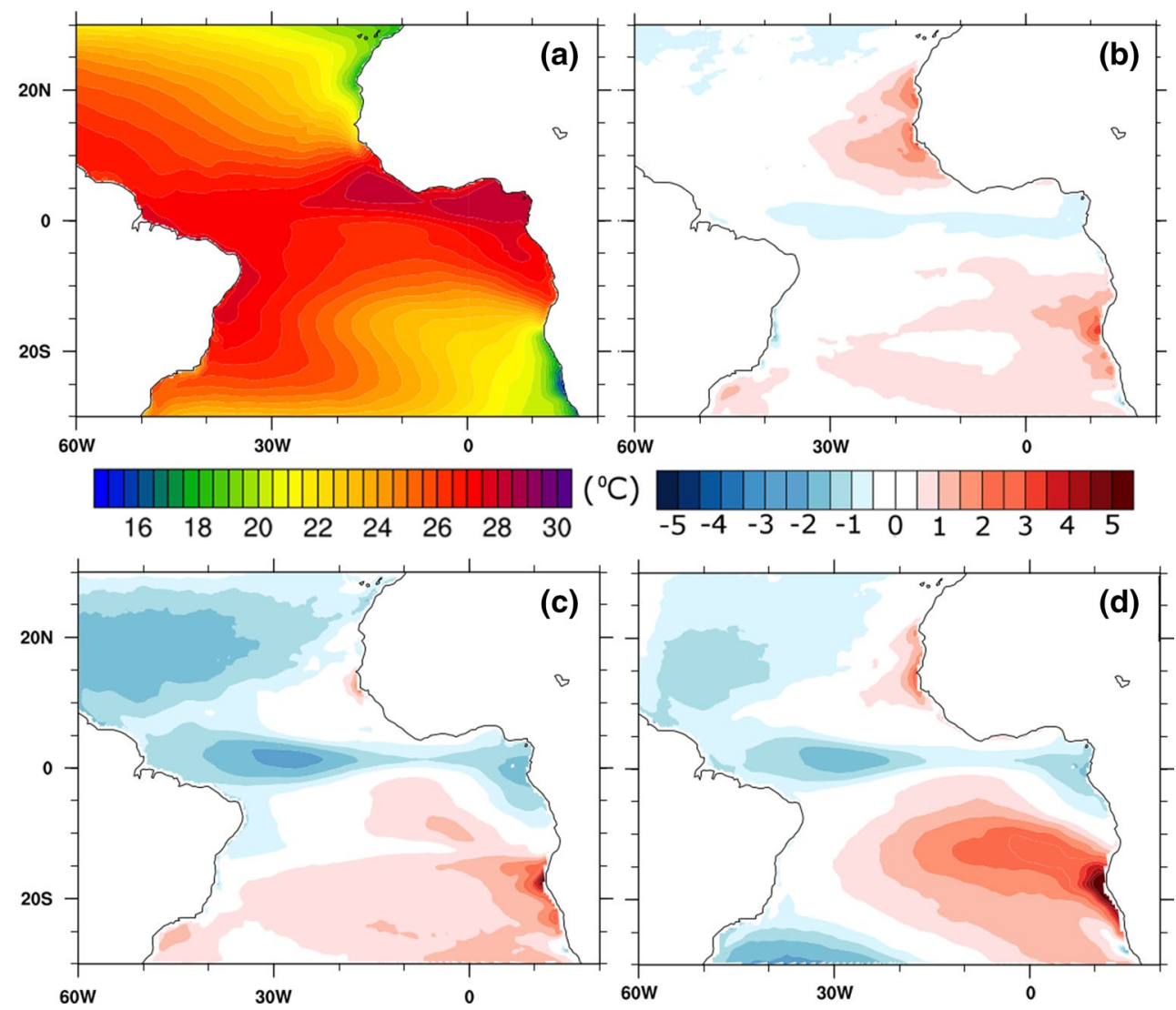
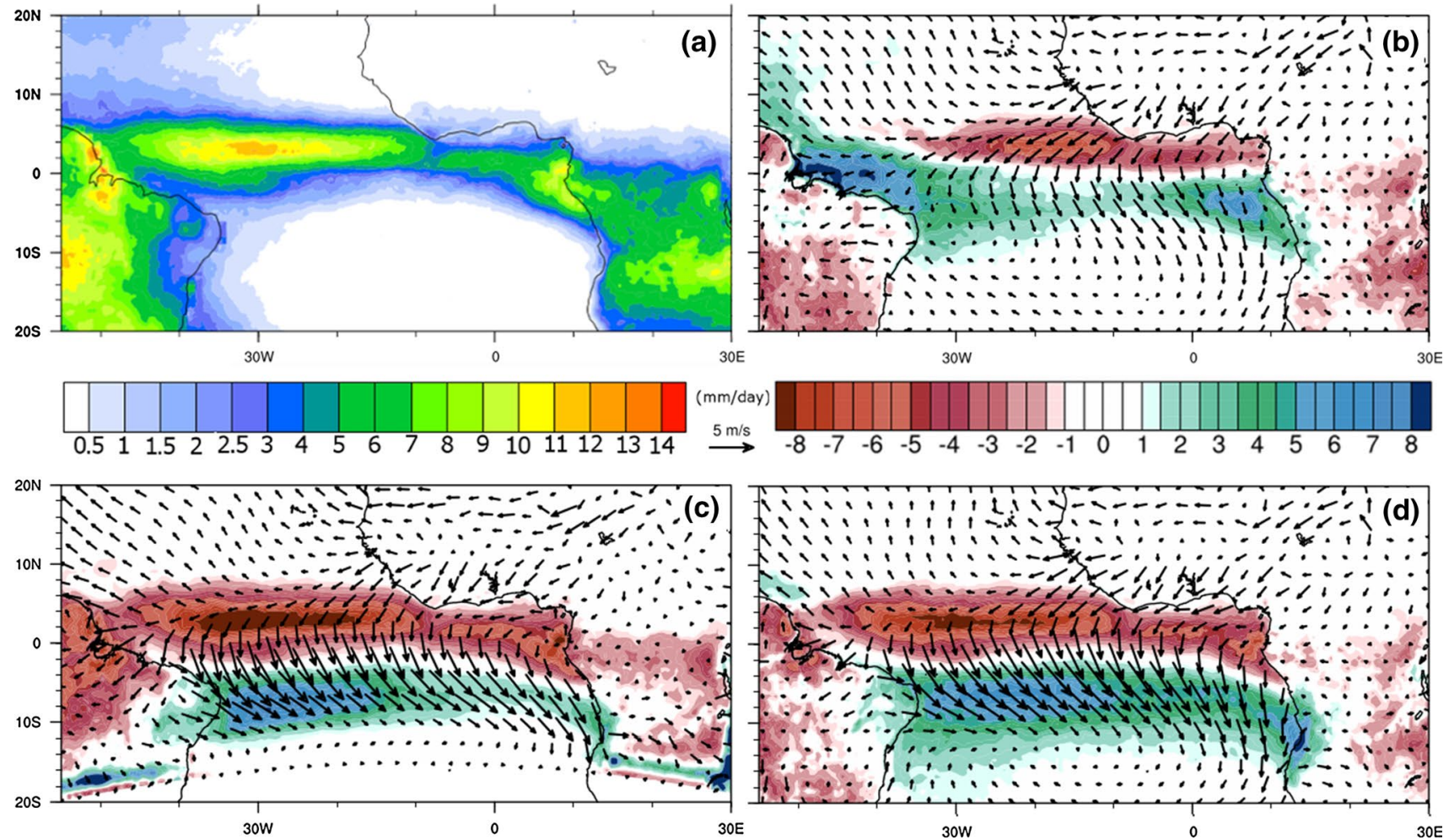

Fig. 4 DJF precipitation. a The TRMM 1998-2012 climatology. The remaining figures show the difference between DJF 1980-1999 climatology of simulated precipitation and $10 \mathrm{~m}$ wind and the
TRMM 1998-2012 and ERA40 wind climatologies for b AFR50U, c NAT50C and d AFR50C 
Fig. 5 JJA MSLP for the 1980-1999 period. a ERA 40 climatology. The remaining figures show the JJA difference with ERA40 for coupled and uncoupled simulations: $\mathbf{b}$ AFR50U, c NAT50C, and d AFR50C. Pressure is given in $\mathrm{hPa}$. Note that the NAT domain extends roughly to $15 \mathrm{~S}$
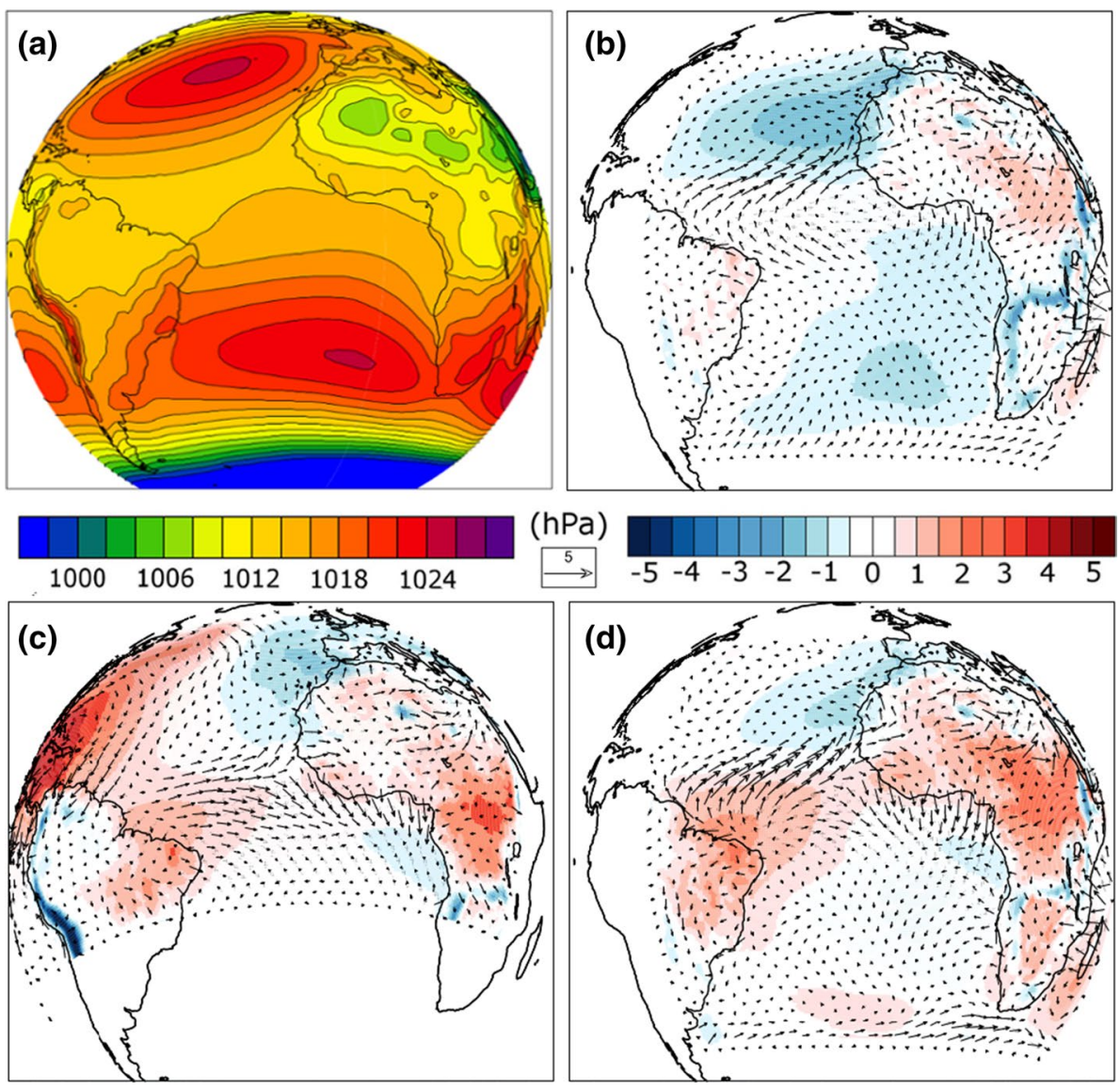

Atlantic Anticyclone, reach their maximum strength. For instance, the bias patterns in both AFR and NAT sets of simulations are more similar in the equatorial region, and the AFR simulations do not show the cyclonic bias in the SETA region identified for DJF. The pattern of the negative anomalies of MSLP to the south of the Gulf of Guinea for the coupled runs resemble those of the strong positive SST bias, and are weaker for the NAT simulations, with more moderate SST biases (cp. Fig. 6c with d). Our sensitivity studies with different parameterizations further suggest that the improvement of the MSLP biases in AFR50C is associated with a somewhat better simulation of SSTs in the Gulf of Guinea (not shown).

The SST biases can be associated with a particular feature of the atmospheric or oceanic component of our coupled system. To explore these possible connections, coupled and uncoupled simulations can be compared. A particular uncoupled simulation (ERA-40 driven) can show biases inherent to the specific model formulation or parameterizations. These biases can be reduced or enhanced by the coupling, revealing the possible mechanisms depending on how they affect the simulated SAA and SSTs.

In DJF, the uncoupled atmospheric model in the AFR domain shows MSLP and surface wind biases that broadly resemble those found in the coupled setup-compare
Figs. $2 b$ versus $d$ and $4 b$ versus $d$. This bias is in fact amplified by the coupling, which further weakens the MSLP in the SAA region. On the other hand, the coupling increases the MSLP values over land, and near the equator.

In JJA, the simulated SAA reaches its maximum strength and the ITCZ its northernmost position (Fig. 5). During this season, the atmospheric uncoupled run in the AFR domain presents a weaker than ERA40 SAA core and small MSLP biases, which are negative in the Atlantic and mostly positive over the African continent (Fig. 5b). The coupling increases the MSLP over the whole domain, reducing the negative biases over the Atlantic at the expense of the growth of positive biases over Africa and the western equatorial Atlantic (Fig. 5d). The northeasterly trade winds are underestimated both in the NAT and AFR simulations, and this likely reduces the contribution of the northern monsoons to the SAA strengthening in austral winter. In our model, this pattern is independent both from parameterizations and resolution.

In this season, the uncoupled TR04 simulation exhibits a zonally stretching cold bias in equatorial Atlantic Ocean. Ocean-atmosphere interaction causes the bias to extend to the north of North West Africa and to the south in the western equatorial Atlantic, both in AFR and NAT coupled simulations (Fig. 6). In SETA, TR04 shows warm biases that 
Fig. 6 JJA SST for the 1980-1999 period. a The Reynolds OISST V2climatology. The remaining figures show the difference of simulated JJA SST climatology with OISST V2 for b TR04, c NAT50C and d AFR50C
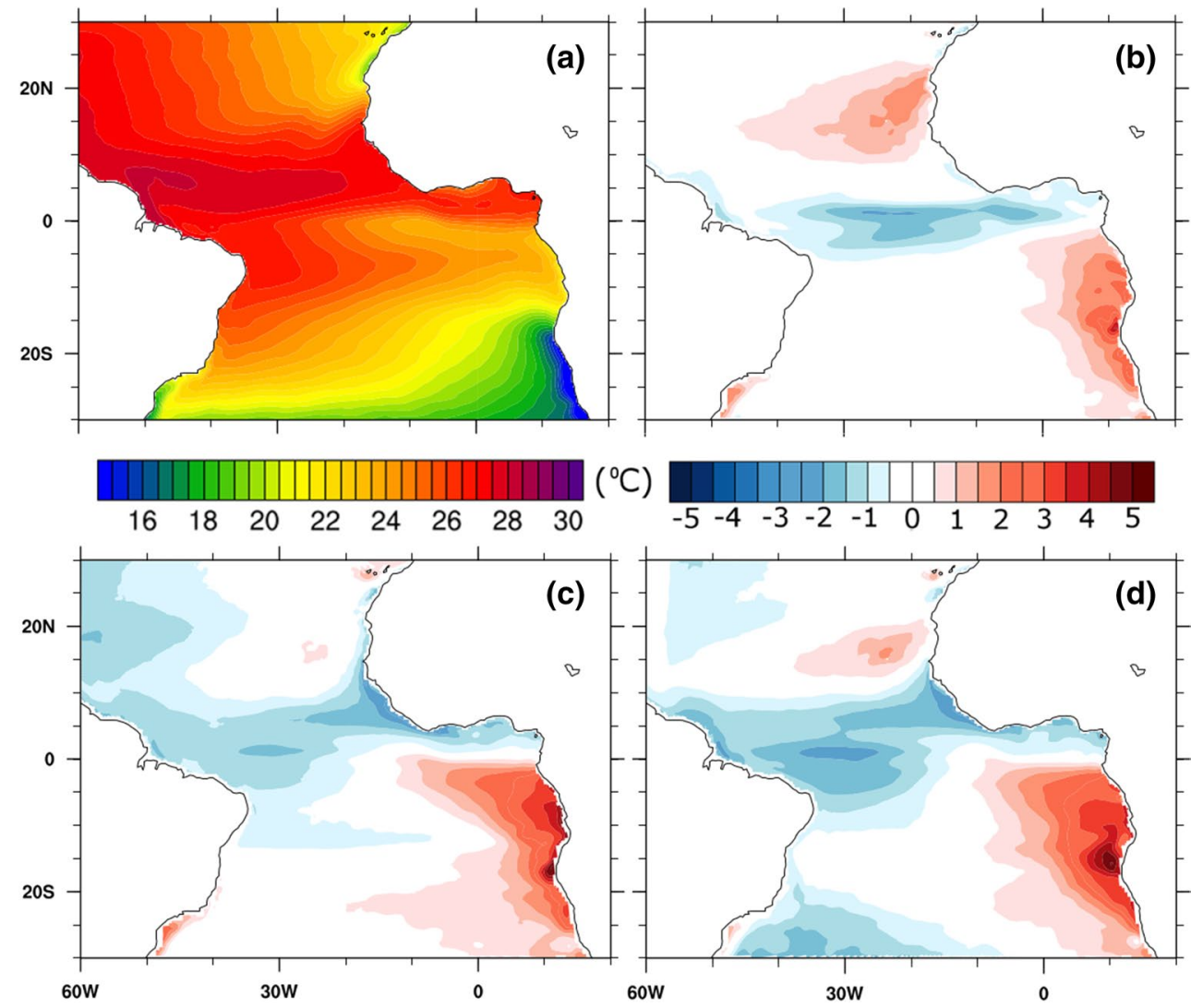

$\left.{ }^{\circ} \mathrm{C}\right)$
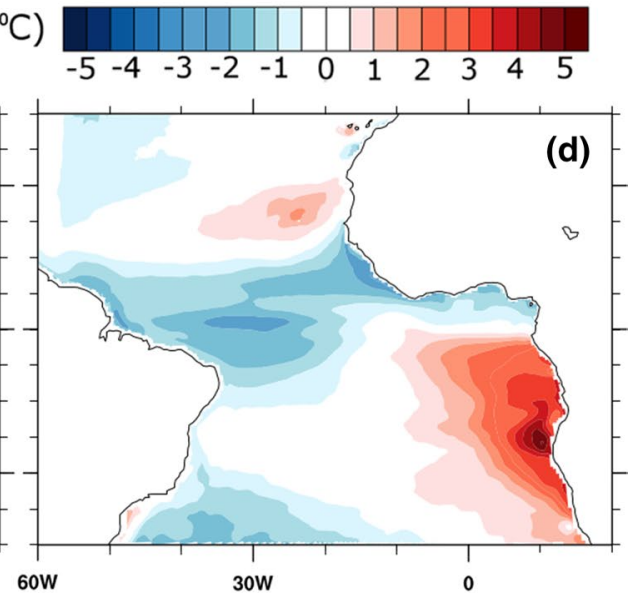

stretch from the Benguela upwelling system up to the equator, which remain mainly close to the coast. These biases, that in the uncoupled run could be caused by errors in the prescribed momentum fluxes, are strengthened by the coupling. They do not extend as far into the basin's interior as in DJF but expand to the interior of the basin as approaching to the equator, especially in NAT.

The opposite occurs for the warm biases in the northern tropical Atlantic that extends further into the ocean interior in JJA. The SST warm biases in the northern tropical Atlantic show similar structure in NAT and AFR, but with larger values in the latter.

It is worth noting the existence of a clear equatorial westerly wind bias in the coupled runs in JJA that is not evident in the uncoupled AFR (Fig. 7). Some authors (Patricola et al. 2012; Richter et al. 2012b; Xu et al. 2014) postulate that westerly wind bias over the equatorial Atlantic contributes to the insufficient vertical temperature stratification and warm SST biases in the Benguela upwelling system. In AFR50C, precipitation shows dry biases over Africa and dry biases just north of the equator and wet biases further north (Fig. 7). The positive precipitation bias can be related to the positive SST anomaly off northern Africa. This SST bias is also present in the standalone ocean simulation TR04 and is enhanced in the coupled simulations.
The precipitation bias north of the equator in boreal winter is reflected in the northward ITCZ shift in the coupled runs (Fig. 8), which is located too far north from boreal winter through summer, and retracts southwards too early in autumn (especially in AFR50C). This suggests that the ocean-atmospheric feedback involves SST, evaporation and wind. Over the Gulf of Guinea, the biases could be related to a mechanism similar to the Bjerkness feedback: the excessive precipitation over the Gulf of Guinea is apparently the main cause of the equatorial westerly wind bias in the central and western Atlantic.

\section{Analysis of SST and ocean circulation}

The ocean response to the coupling in terms of SST anomalies is linked to changes in the regional ocean circulation and present strong seasonal variability. The role of the ocean heat transport in the TA climate has been explored e.g., by Foltz and McPhaden (2006), Joyce et al. (2004), and Seager et al. (2001). They found that the most important effect of horizontal advection is the damping of SST anomalies in the subtropical Atlantic, although Seager et al. (2001) also stresses the importance of the advection by the mean ocean circulation for the propagation of SST signals. 

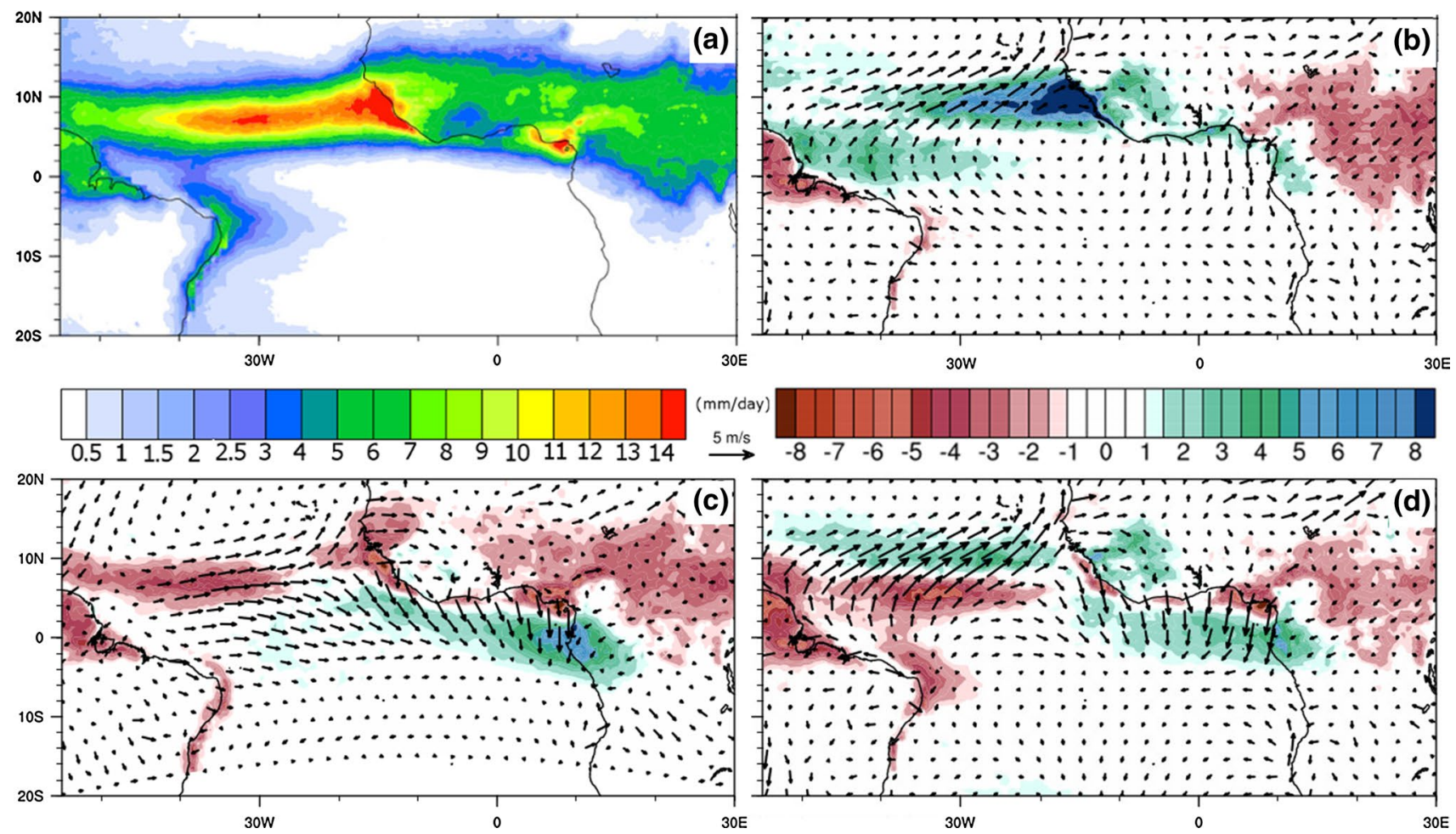

Fig. 7 JJA precipitation. a The TRMM 1998-2012 climatology. The remaining figures show the difference between JJA 1980-1999 climatology of simulated precipitation and $10 \mathrm{~m}$ wind and the TRMM 1998-2012 and ERA40 wind climatologies for b AFR50U, c NAT50C and d AFR50C

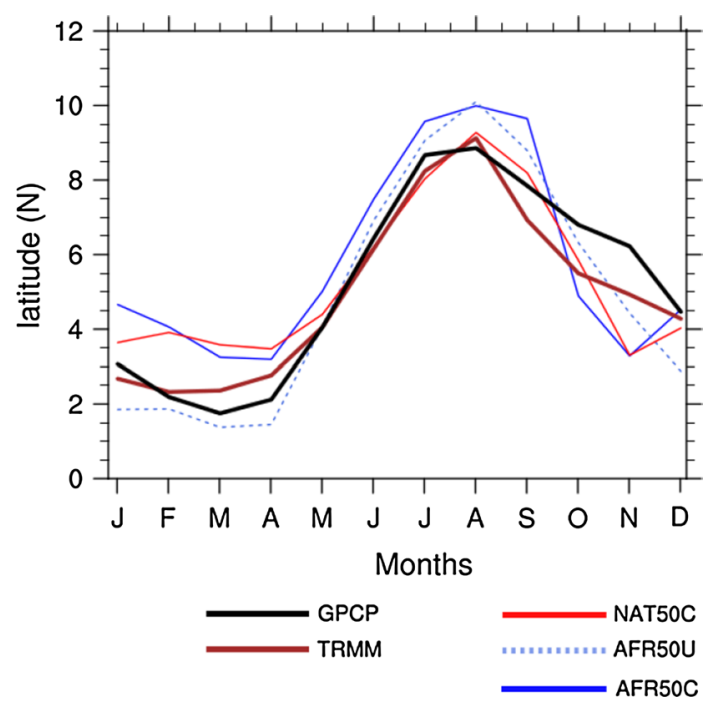

Fig. 8 Seasonal cycle of the position of the tropical Atlantic ITCZ. The position of the ITCZ is defined as the latitude (between $0^{\circ}$ and $20^{\circ} \mathrm{N}$ ) of the maximum of the precipitation averaged between $30^{\circ} \mathrm{W}$ and $10^{\circ} \mathrm{W}$

The uncoupled TR04 simulation shows a cold bias at the equator and a moderate warm bias at the Angola Benguela Front Zone. According to Xu et al. (2014), an overshooting of the Angola Current (AC), a feature common to many ocean models, can cause this warm bias. To further analyze the interplay of the SSTs and the ocean circulation, we explore the seasonal cycles in the uncoupled TR04 and the coupled NAT50C and AFR50C configurations.

The uncoupled ocean model TR04 simulates the tropical Atlantic SST seasonal cycle reasonably well (Fig. 9, upper row), with biases within half a degree for most of the tropical Atlantic for all seasons. Larger positive biases are found in the northeastern tropical Atlantic, with two local maxima in MAM at the Guinea Dome and south of Cape Blanc (cf. Fig. 1 for locations).

These positive northeastern tropical Atlantic biases weaken in JJA and almost disappear in SON, but reinforce again in DJF, which points to deficiencies in the simulation of the mixed layer depth in the area of the Guinea Dome (Doi et al. 2010). Negative biases occur near the Equator, largest during JJA and SON, while they almost vanish in DJF and MAM.

The most remarkable differences with Reynolds SST (Reynolds et al. 2007) are found on the southeastern tropical Atlantic. The larger departures are close to the Angola Benguela Front Zone with a year-round local maximum off Cape Frio (cf. Fig. 1c), indicative of a too southward position of the Angola Benguela Front in TR04, as reported for the ensemble of CMIP5 models by Xu et al. (2014). In DJF, the maximum SST bias is restricted to a small area by the African coast by Cape Frio. During MAM and JJA, the 

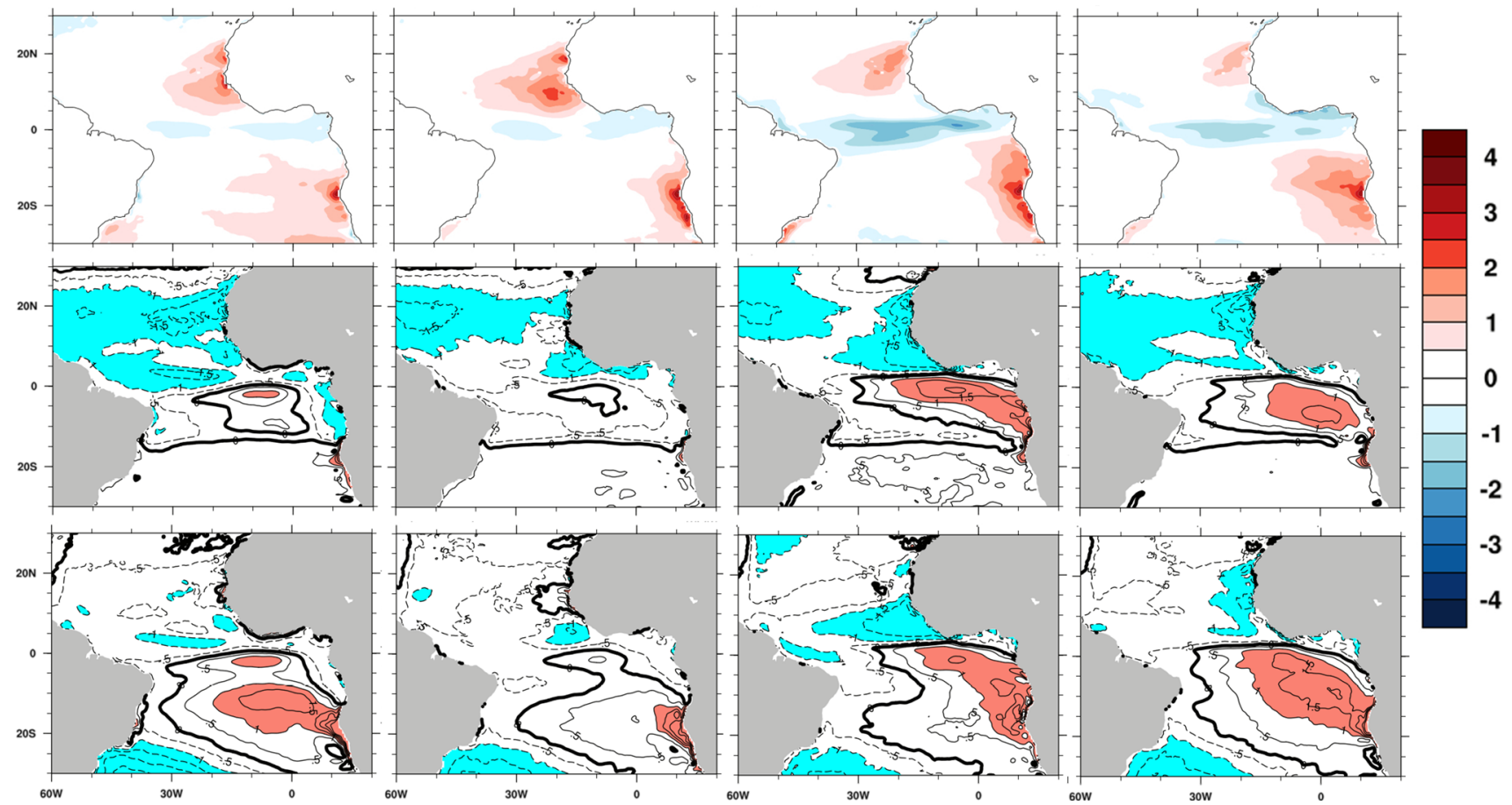

Fig. 9 Upper row seasonal SST biases of TR04 against OISSTV2. Middle row NAT50C minus TR04. Lower row AFR50C minus TR04 from left to right, DJF, MAM, JJA, SON

maximum SST bias extends as a narrow coastal strip southward along the Benguela Upwelling System down to $25^{\circ} \mathrm{S}$, while in SON this coastal warming weakens and the warm anomaly is shifted towards the ocean interior.

In the western part of the southern tropical Atlantic, the NAT50C SSTs are slightly colder than in TR04 but is generally warmer in the central part throughout the year. NAT50C SSTs are clearly cooler along the Equator and along the coasts of the Angola Basin in DJF, but warmer in the central-eastern equatorial Atlantic and along the Benguela Upwelling System. These differences decrease in JJA and SON, when the SST in the Gulf of Guinea is about $1{ }^{\circ} \mathrm{C}$ warmer in NAT50C than in TR04: this offsets the cold TR04 bias in the eastern equatorial ocean $\left(5^{\circ} \mathrm{N}-5^{\circ} \mathrm{S}\right)$ but increases the warm bias in the southeastern low latitude tropical ocean $\left(5^{\circ} \mathrm{S}-10^{\circ} \mathrm{S}\right)$. The impact of the coupling in the AFR domain is more prominent, as most of the southern tropical Atlantic shows consistently warmer SSTs than the uncoupled TR04. The warm bias exhibits the maximum westward and southward extension for DJF and SON, reaching up to $4{ }^{\circ} \mathrm{C}$ in the Benguela Upwelling System and being significant throughout the year, except MAM, in SETA. As it could be expected, differences between NAT and TR04 outside of the coupling domain (roughly south of $15^{\circ}$ ) tend to be lesser due to the bulk heat fluxes.

These SST biases lead to a modification of the zonal SST gradients in the coupled simulations, as seen in the departure of the zonal mean depicted in Fig. 10. The DJF Reynolds climatology shows a clear negative zonal SST gradient through the whole southern tropical Atlantic with the exception of the easternmost region between the Angola Benguela Front and the Gulf of Guinea $\left[15^{\circ} \mathrm{S}-0^{\circ}\right]$, which presents a weak positive zonal SST gradient.

During austral winter months (JJA), the negative zonal SST gradient is enhanced, particularly at more equatorial latitudes. As a consequence, the area of positive SST gradients shrinks to a small band along the equator within the Gulf of Guinea as a consequence of the seasonal equatorial Atlantic cold tongue appearance (Weingartner and Weisberg 1991). The standalone TR04 does not show big differences against the climatology, although the austral winter reinforcement of the SST gradient is not strong due to an insufficient cold tongue development. An evident effect of coupling is that the SST zonal gradient between the Angola Benguela Front and the Gulf of Guinea does not change sign from DJF to JJA (see Fig. 10, AFR50C). AFR also presents a weaker zonal SST gradient in the whole SETA for JJA (Fig. 10).

The implications to the surface ocean circulation are depicted in Fig. 11. As suggested by Xu et al. (2014) based on numerical results, our AFR runs also provide evidence of a clear connection between Angola Benguela Front warm bias and the strength and southward extension of the south flowing Angola current. 


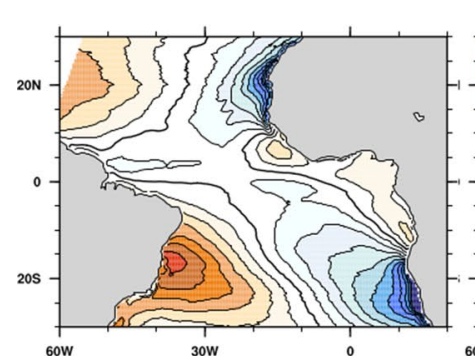

(a)

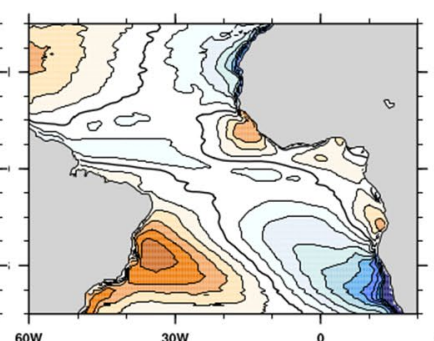

(b)

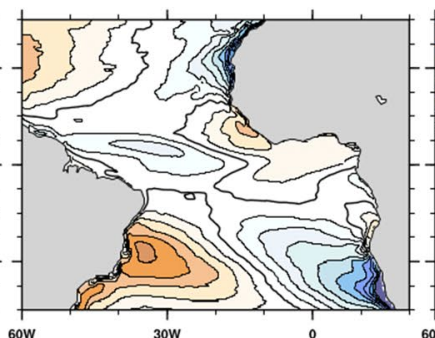

(c)

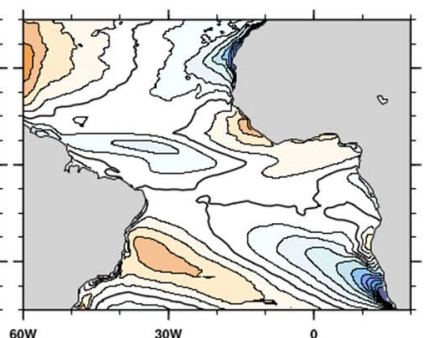

(d)
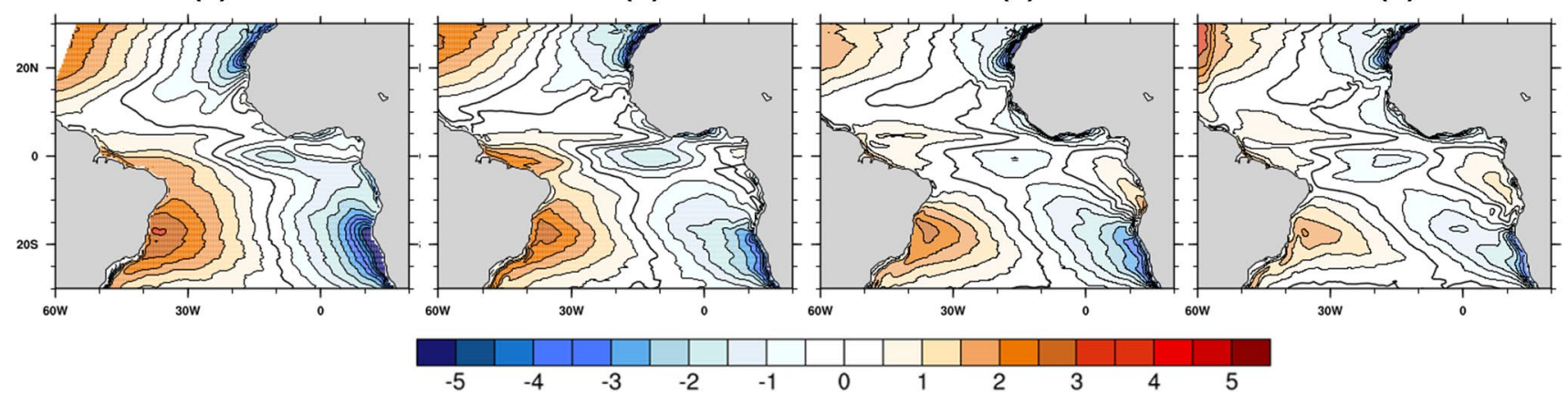

60w 30w

5

Fig. 10 Departure from the zonal mean SST for each latitude (which illustrates the SST zonal gradient) for a OISSTV2, b TR04, c NAT50C, d AFR50C for DJF (upper row) and JJA (lower row). The seasonal means are calculated for 1980-1999
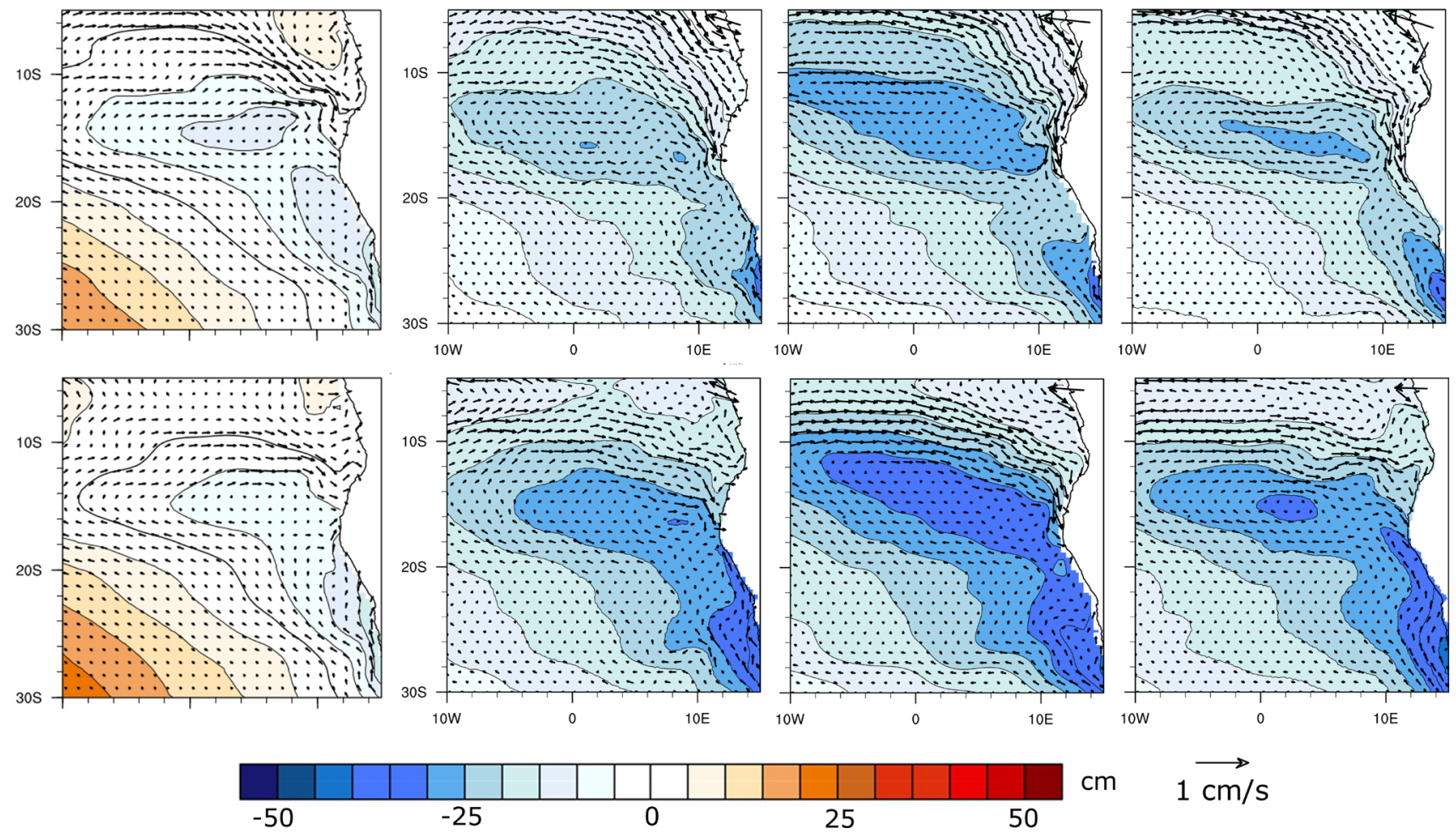

$1 \mathrm{~cm} / \mathrm{s}$

Fig. 11 SSH (contours) and geostrophic velocities (vectors) for CFSR, TR04, NAT50C, AFR50C averaged over the 1980-1999 period. Upper row DJF, lower row JJA

Geostrophic currents in CFSR show the northward Benguela current that meets with the Angola current at the position of the Angola Benguela Front (between $16^{\circ} \mathrm{S}$ and $17^{\circ} \mathrm{S}$ ). The northward current is in geostrophic balance with an onshore pressure gradient likely caused by coastal upwelling, which reduces the sea surface elevation locally 


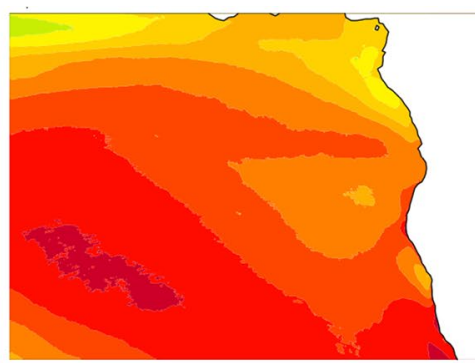

(a)
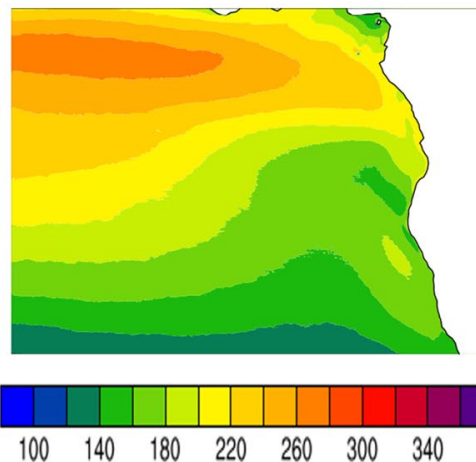

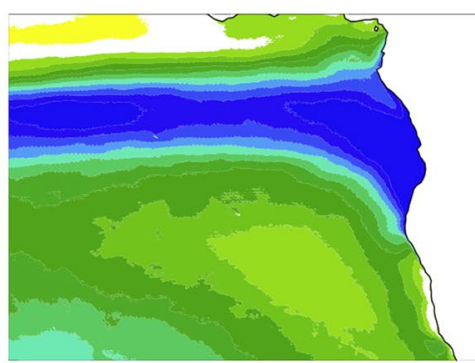

(b)

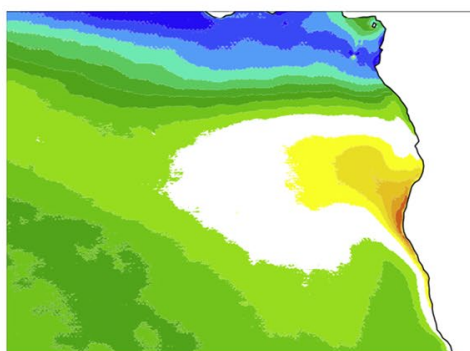

$\left(\mathrm{W} / \mathrm{m}^{2}\right)$

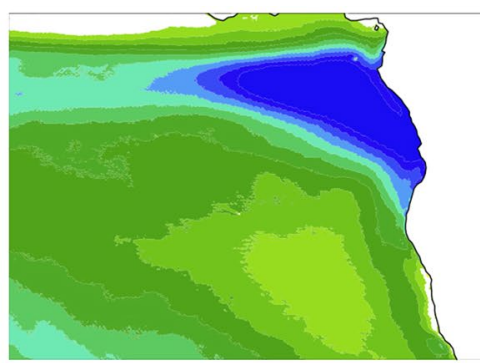

(c)
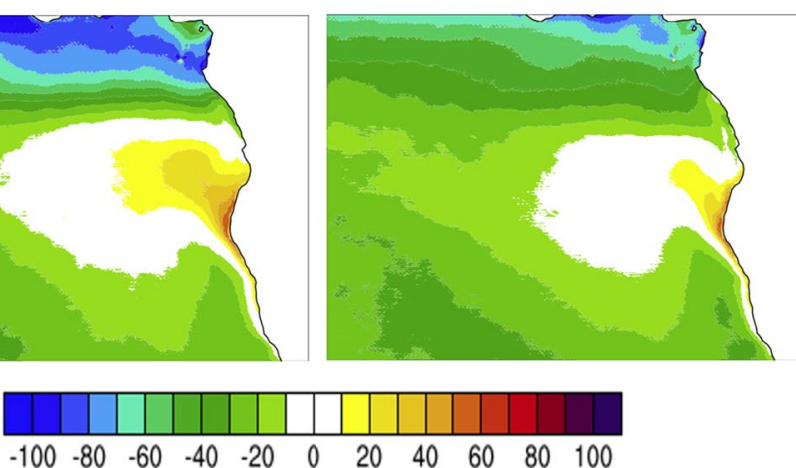

Fig. 12 Surface incoming short wave radiation flux $\left(\mathrm{W} / \mathrm{m}^{2}\right)$ for $1980-1999$ for DJF (upper panels) and JJA (lower panels) a SARAH-MA climatology. The remaining figures show the biases with respect to SARAH-MA for b AFR50C and $\mathbf{c}$ AFR50U

(Philander and Yoon 1982), while the Angola current seems to be related to cyclonic wind stress curl (Colberg and Reason 2006), which is prevalent north of $15^{\circ} \mathrm{S}$ in the atmospheric component of the CFSR reanalysis (not shown) and experiences a strong seasonality with a maximum in DJF. The uncoupled TR04 shows a wider and stronger Angola current in DJF, but its southern limits are close to CFSR.

A different situation is found in the coupled runs: both setups show a clear overshooting of the Angola current, reaching as far south as $26^{\circ} \mathrm{S}$ in AFR in DJF, while in JJA it is NAT that reaches the southernmost position (Fig. 11). This causes a southward shift of the Angola Benguela Front and larger warm SST bias in that area. This strengthening of the southward flow in AFR simulations can be related to reduced upwelling-favoring winds associated with a weaker SAA, and a stronger negative wind stress curl north of the Angola Benguela Front (Xu et al. 2014). Richter (2015) hypothesizes that westerly wind biases on the equator may also be partly responsible for the overshooting of the Angola current in GCMs because they lead to higher than observed sea level at the eastern boundary contributing to the strength of the current. In turn, warmer water is transported to the interior of the southern tropical Atlantic by advection and eddy transport related to the SEC, spreading the warm bias to this region (see Fig. 9).

In austral winter (JJA), when the SAA is of similar magnitude in both domains, the impact of the SAA on the ocean circulation is harder to discern. The spatial pattern of the Sea Surface Height and the associated geostrophic currents in both sets of simulations for JJA are similar to CFSR (Fig. 11). Therefore, the contribution of the transport out to the central basin to the biases in JJA is apparently not as important for JJA as for the austral summer.

Another proposed mechanism explaining the warm SST biases in the eastern subtropical oceans is related to the poor skill of the GCMs to reproduce the observed stratocumulus cloud fraction, leading to a modification of the surface radiative balance (e.g., Ma et al. 1996). In the AFR runs, the bias in downwelling surface radiation is negative over almost the entire Atlantic Ocean basin except off the southwest African coast in JJA (Fig. 12). The negative bias is due to an overestimation of the cloud cover. Additional experiments with the coupled model suite were carried out with increased thresholds for sub-grid cloud formation and reduced altitudes for cloud top before the cloud may rain. The large negative bias in radiation was removed due to a cloud cover decrease, but at the expense of a significant overestimation of rainfall in the ITCZ (not shown). In these experiments with increased and more realistic solar irradiance over the Atlantic Ocean basin, the patterns of the SST warm bias remained the same, thus corroborating the hypothesis of a dominant role of the response of the ocean dynamics to changes in surface wind stress. However, the increased local radiative forcing enhanced the positive SST anomalies in amplitude (not shown). Still, note that a positive radiation bias is observed west of the Angolan 
in JJA in the AFR simulations (Fig. 12), implying that an impact from anomalously low cloudiness in this marine stratocumulus zone to the warm bias is very likely. However, its exact contribution would require a thorough study of surface and ocean mixed layer energy budgets which is beyond the present study.

\section{Relevance of the thermocline}

The alongshore biases north of the Angola Benguela Front detected in the uncoupled simulations can be related to ocean model deficiencies in simulating the thermocline along the Angola coast, and could be remotely linked to biases in the equatorial thermocline (Lübbecke et al. 2010). They may also arise from inaccuracies in the data used to drive the ocean model. While the overshooting of the Angola current contributes to the biases south of the Angola Benguela Front, similar biases in the SETA SSTs are also found in experiments with the NCEP Coupled Forecast System (CFSR; Huang et al. 2007) and these have been attributed to a failure in simulating the sharp thermocline within the Benguela upwelling system (Xu et al. 2014). In order to gain more insight into the role of the upper ocean in the simulated SSTs, we compare the seasonal cycle of model SST, and the thermocline (represented by the depth of the $23{ }^{\circ} \mathrm{C}$ isotherm) with the corresponding data from Reynolds OISSTV2, PHC and the GODAS reanalysis for the two key regions (see Fig. 1c): the Angola Benguela Area (ABA: $20^{\circ} \mathrm{S}-10^{\circ} \mathrm{S}, 8^{\circ} \mathrm{E}-15^{\circ} \mathrm{E}$ ) to represent the Angola Benguela Front (and the center of the Benguela Niños), and the Atlantic3 region (ATL3: $3^{\circ} \mathrm{S}-$ $\left.3^{\circ} \mathrm{N}, 20^{\circ} \mathrm{W}-0^{\circ} \mathrm{E}\right)$ to represent the equatorial Atlantic cold tongue. Additionally, we define the South Eastern Equatorial Atlantic (SEEA: $15^{\circ} \mathrm{S}-5^{\circ} \mathrm{S}, 10^{\circ} \mathrm{W}-8^{\circ} \mathrm{E}$ ) to represent the region where the uncoupled TR04 bias off the African coasts expands in the coupled models.

The standalone TR04 provides a good simulation of the seasonal cycle of SST in the ATL3 region (Fig. 13). The model captures well the evolution of the seasonal cycle, reaching its maximum in March-April and featuring a minimum during July-August. Still, it is consistently colder than both GODAS and OISSTV2 through the year. This colder SST is associated with a shallower thermocline (Fig. 13). Both the AFR and NAT setups also simulate well the seasonal cycle of SST. In general, the coupling increases the SST in ATL3, especially in the second half of the year. This warming is similar for both setups, up to $2{ }^{\circ} \mathrm{C}$ in JJA. Therefore, the simulated ATL3 SST is closer to both observations and reanalysis in NAT and AFR runs than in the standalone TR04. This warmer SST in the coupled runs is associated with a deeper thermocline in these simulations compared to the standalone TR04 (Fig. 13) for the
MAM and JJA seasons. A possible explanation for this in JJA is as follows: during these seasons, a coupled mode is excited, similar to the delayed oscillator operating interanually in the Pacific (Ding et al. 2009; Burls et al. 2011) and a deeper mean thermocline leads to a slower SST response. Moreover, the effect of the equatorial wind bias should be considered for the equatorial upwelling (which is reduced given a westerly wind bias). Additionally, the deeper thermocline in the coupled setups could weaken the Ekman feedback, turning the SST less sensible to the cooling by wind forcing. During austral winter and spring, with the shoaling of the thermocline due to the seasonal strengthening of the winds, local forcing by the equatorial zonal wind component and together with vertical advection of colder subsurface water across the thermocline from the ocean interior driven by Bjerknes-like ocean-atmosphere feedbacks play the main role in the middle and western Atlantic (Burls et al. 2011). For this season, two other mechanisms for easterly wind acceleration over the equatorial Atlantic are identified: (1) the pressure gradients induced by monsoon heating over western Africa and the northern tropical Atlantic is limited to the eastern Atlantic south of West Africa; and (2) the equatorward momentum advection is a significant contributor across the basin. The accelerated easterlies contribute to the equatorial cooling by inducing upwelling and by shallowing the thermocline in the east (Okumura and Xie 2006). Richter et al. (2012b) showed that JJA SST biases in the eastern Equatorial Atlantic in the CCSM global coupled model can be associated with a weakened east-west tilt of the thermocline due to a deeper thermocline in the eastern half of the equatorial Atlantic, which develops in response to a reduced strengthening of the MAM zonal wind stress.

In JJA, the SST is warmer in the east and colder in the west compared to the uncoupled run for both AFR and NAT domains. These improvements in the simulated surface temperature are associated with a shallower thermocline in the west and to a deeper thermocline in the east. This behavior is apparently associated with a weaker simulated easterly wind stress in MAM compared to ERA40 (Fig. 14). In both coupled simulations, the weaker easterlies in the equatorial band during MAM cause a shallower thermocline in the western part of this region, and a deeper thermocline in the center and the east. The ocean-atmosphere feedbacks active during the JJA season lead to a further weakening of the thermocline tilt and a warmer surface temperature in the eastern equator.

In the ABA region, AFR simulations show a much higher SST all across the year that is also associated with a deeper thermocline (Fig. 13). In the SEEA region, warm SST is associated with a deeper mean thermocline from July to December (causing a decrease of the interannual variability). As in the equatorial region, the remote forcing is also 


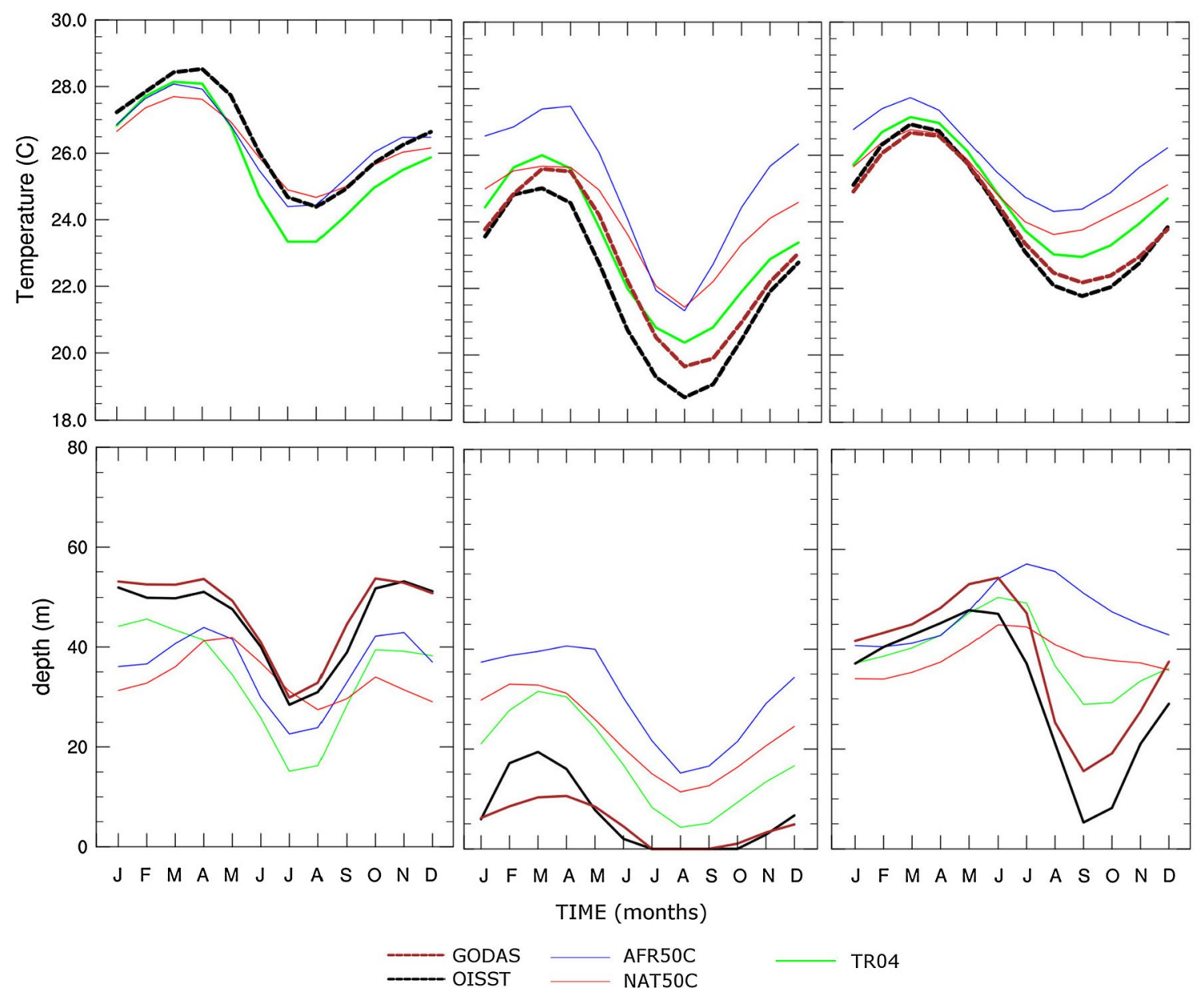

Fig. 13 SST (upper row) and $23{ }^{\circ} \mathrm{C}$ isotherm (lower row) seasonal cycle in the ATL3 region (left), the ABA (center) and the SEEA region (right) for OISSTV2 (black dashed line), CFSR (brown dashed line), TR04 (green line), and for the NAT (reddish lines) and AFR (bluish lines) coupled setups

western thermocline shallower in AFR compared to both TR04 and NAT simulations. The weaker SAA in AFR thus appears to have a strong effect in the vertical structure of the upper ocean layers across the subtropics. For example, the importance of a realistic simulation of the upwelling along the South African coast for a correct representation of the equatorial mixed layer temperature has been recently highlighted by Vizy and Cook (2013) using a coupled regional climate model/mixed layer ocean model. They found that the Atlantic cold tongue is much improved due to the horizontal advection of cold upwelled waters from the coastal South Atlantic with some contribution from vertical entrainment of cold water from below the mixed layer. Using the heat balance in the mixed layer, Hazeleger and Haarsma (2005) showed that a negative bias in the equatorial cold tongue can be attributed to entrainment flux at the base of the oceanic mixed layer. An enhanced entrainment deepens the mixed layer and causes strong reduction in the upper ocean divergence in the central equatorial Atlantic. 
(a)

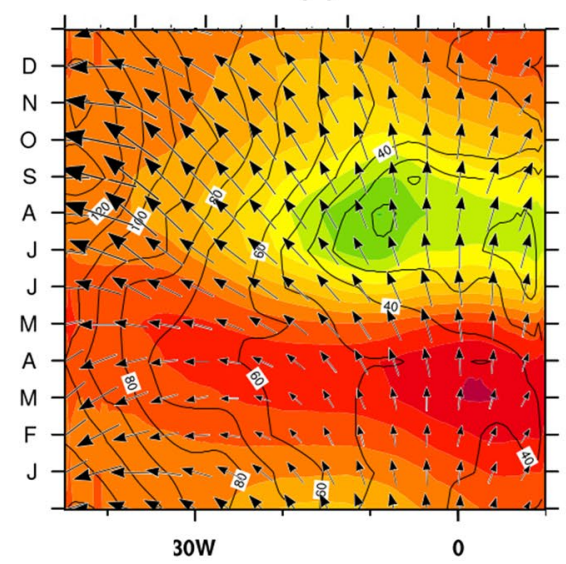

(d) (b)

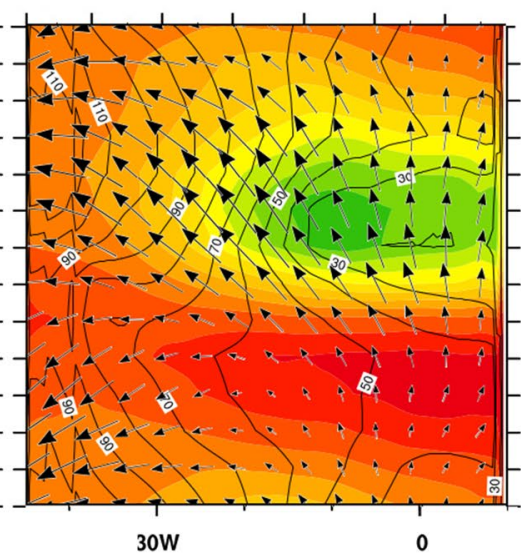

(e)

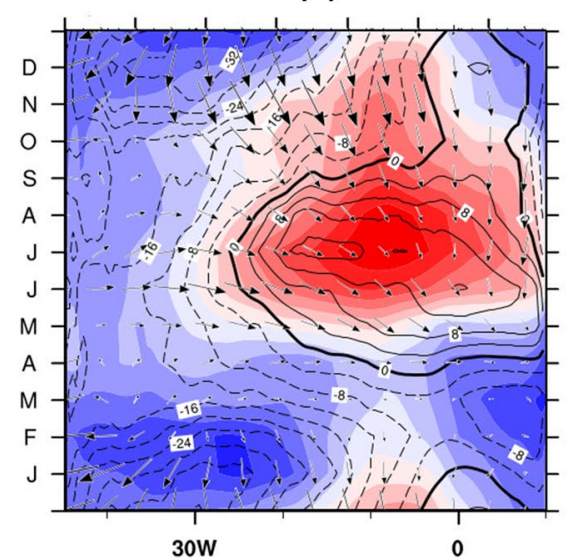

$30 \mathrm{~W}$

0

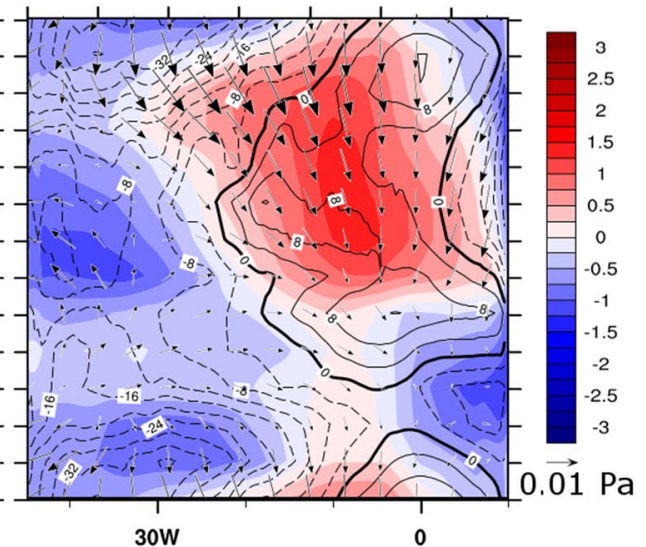

Fig. 14 Upper row seasonal cycle of SST (shaded), 23C isotherm (contours) and winds (vectors) averaged over the equatorial band $3 \mathrm{~S}-3 \mathrm{~N}$ for a IOSSTV2 SST, PHC temperatures and QuickSCAT winds. b GODAS 1980-1999 climatology with NCEP winds and c

\section{A coupling mechanism for the southern tropical Atlantic}

The advection of the relatively cold water by the eastern Benguela current seems to play an important role in the thermal balance of the southern tropical Atlantic, and misrepresentations in the simulation of this transport could contribute to the warm bias there. Moreover, an inadequate representation of the transport can affect the representation of the whole SETA climate. Seager et al. (2003) suggested that a strong subtropical east-west SST gradient is important for the large-scale manifestation of the oceanatmosphere feedback responsible for the SAA strengthening. This east-west SST gradient is composed in the western part by a warm patch located between $20^{\circ} \mathrm{S}$ and $10^{\circ} \mathrm{S}$ due mainly to the transport of warm water by the Brazil current and a band of cold water in the east mainly due to the transport by the Benguela current and associated upwelling. The extension and position of this patch of cold

(c)

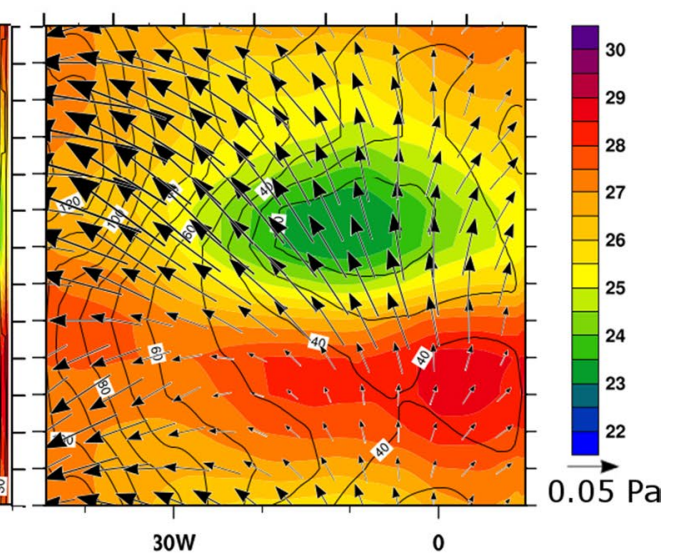

TR04 1980-1999 climatology with ERA40 winds. Lower row seasonal cycle of SST (shaded), $23{ }^{\circ} \mathrm{C}$ isotherm (contours) and winds (vectors) differences between NAT50C and TR04 (left), and AFR50C and TR04 (right) averaged over the equatorial band $3 \mathrm{~S}-3 \mathrm{~N}$

SST is largely determined by the location of the Angola Benguela Front.

In our simulations, a weaker DJF SAA is associated to a strong southward flowing Angola current with an insufficient equatorward advection of colder water by the Benguela current and as a consequence, a southward displacement of the Angola Benguela Front. This is documented in Fig. 11, which depicts the geostrophic velocity in the SETA for the CFSR reanalysis and our simulations. The resultant warming leads to an east-west gradient that is slightly weaker in NAT and much weaker in AFR than the gradient for standalone TR04 (Fig. 10).

In AFR this is true not only in DJF but in all seasons, and is related to much stronger warm anomalies in the eastern part of SETA that extend further west compared to the TR04 and the NAT simulations. Figure 9 illustrates the seasonality of these differences: for all seasons, the SST is higher for AFR than for TR04 and NAT all across the southern tropical Atlantic, except for the western subtropics. 

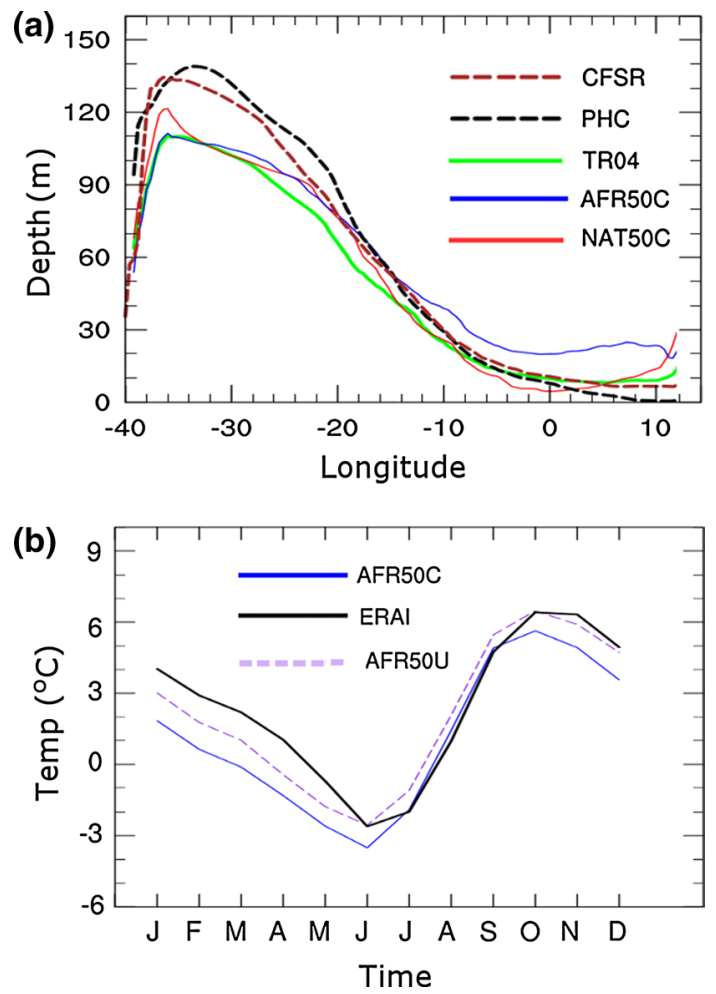

Fig. 15 a JJA 1980-1999 mean of the depth of the $23{ }^{\circ} \mathrm{C}$ isotherm, representative of the thermocline, averaged over the meridional band (20S-10S). The tilt of the thermocline is correlated with the strength of the winter SAA. b Seasonal cycle of the difference between land surface temperature and sea surface temperature averaged over the rectangular region $(40 \mathrm{~S}-10 \mathrm{~S}, 30 \mathrm{~W}-40 \mathrm{E})$

In the atmosphere, the weaker AFR SAA and the associated anomalous cyclonic circulation leads to weaker atmospheric cooling in the eastern ocean by subsidence over the warmer SST, and to slightly less warming in the southwestern Atlantic, in the region of the South Atlantic Convergence Zone by a weaker poleward advection of warm air from the equatorial region (Seager et al. 2003). The warmer SST acts in turn as a source of anomalous positive potential vorticity, further weakening the SAA (Miyasaka and Nakamura 2010).

As pointed out before, the austral summer SST for the AFR setup is higher in most of the south eastern tropical Atlantic and these biases may be associated with local (Benguela Upwelling System) and basin-wide feedbacks. In this season the AFR domains show a weaker land-sea thermal contrast that causes weaker alongshore winds in this region compared to ERA40. According to Miyasaka and Nakamura (2010), this could lead to a weaker South Atlantic high pressure system. The weaker local alongshore winds cause a strong southward flowing Angola current and a weaker northward flux of cool water along the South African coast and less upwelling and mixing in the ocean and by the South Atlantic current, warming further the water in the upwelling region. The remote forcing of the westerly bias in the equatorial winds may also contribute to modify the Angola current. The transport of this anomalous warm water off the Angola-Namibian coast by the South Equatorial current results in a net warming of the ocean interior and a warmer equatorial countercurrent. This anomalous warming is partially compensated by the higher heat loss from the ocean to the atmosphere over the cooler regions. The latent heat loss is particularly enhanced over the Gulf of Guinea due to the reduced subsidence. The warm bias is associated with enhanced atmospheric water content transport to this region in the AFR setup. These two factors lead to stronger precipitation over the Gulf of Guinea for the AFR setup. In turn, the atmosphere responds to warm SST bias by creating cyclonic potential vorticity. This potential vorticity contributes to the weakening of the alongshore winds, and as a consequence to the weakening of the SAA. Figure $15 \mathrm{~b}$ illustrates the possible importance of this feedback for the simulation of the SAA: a weaker SAA is associated with a warmer SST.

The above results provide evidence that the seasonal biases in the southern tropical Atlantic SST are stronger when the SAA is weaker. In turn, the simulated SAA could be influenced by the SST biases, through a weaker eastwest zonal asymmetry (see Fig. 10). However, the experiments of Richter et al. (2008) with uncoupled atmospheric models show that imposing an artificial east-west SST asymmetry in the subtropical regions does not change significantly the anticyclone in July. They argue that this fact could indicate that the response for standalone atmospheric models is largely due to local thermodynamic effects. We hypothesize that the coupled feedbacks enhance the atmospheric response to the SST east-west gradient through changes in the South Equatorial Current. Another important factor that can influence their results is that their experiments take place in the austral winter, while the importance of coupling seems to be manifested primarily in austral summer.

On the other hand, our NAT simulations display a region of stronger positive SST deviations from the zonal mean than the uncoupled simulations forced by ERA40 fluxes outside the coupled region. This could indicate that changes in the ocean circulation can be attributed to the coupling, and that the coupled feedbacks seem to make the atmospheric response to changes in the east-west SST gradient stronger and non-local through changes in the south Equatorial currents.

The importance of the described coupled feedbacks is clear in austral summer. The coupling also influences the JJA biases, albeit indirectly, through changes in the simulated thermocline depth. Figures 13 and 15a show that the AFR simulations have a deeper thermocline in the 
Angola Benguela Front Zone. In JJA, when the upwelling is stronger, the deeper thermocline leads to the upwelling of comparatively warmer water, contributing to the strong positive bias.

\section{Conclusions}

We assess the impact of a more realistic simulation of the SAA on the southern tropical Atlantic seasonal cycle with the regionally coupled model ROM. Our two coupled setups (AFR and NAT in Fig. 1b) include the southern tropical Atlantic region. The first domain covers the whole SAA, while the second domain only includes the northern part of the SAA but extends northeastward. With these two different coupled domains, we study the impact of the SAA on the tropical Atlantic seasonal cycle. Our main findings are as follows:

- In DJF the AFR setup shows stronger SST biases off the African coast associated with a weaker SAA compared to both ERA40 and NAT, leading to a cyclonic surface wind bias. The atmospheric biases already present in standalone runs are modified in the coupled setup likely following a mechanism similar to the Wind-Evaporation-SST feedback (cf. Richter and Xie 2008).

- The mechanisms responsible for the identified circulation biases in the tropical Atlantic are different for the DJF and JJA seasons. The differences in simulated MSLP and SST are smaller in JJA, when the SAA reaches its maximum strength.

- In DJF, both local (along the Angola Benguela Front Zone) and basin wide ocean-atmosphere feedbacks (that could involve the ocean transport and the SAA) seem to influence the SST biases. A weaker SAA modifies the advective regime along the southern African coast, with a too strong Angola current bringing warm waters too far south, and a reduced northward flux of cold waters by the South Atlantic current. Together with a decrease in upwelling and mixing, and with possible remote influences from the equatorial westerly wind bias, this yields an anomalous warming within the upwelling region that spreads into the ocean interior by means of the South Equatorial current. These SST biases feedback onto the atmosphere through the generation of cyclonic potential vorticity that lessen the winds and, therefore, the SAA

- In JJA, a too deep thermocline seems to be the most important factor for the SST biases. A deeper thermocline in the Angola Benguela Front Zone region in the AFR simulations leads to the upwelling of warmer water that contributes to the strong positive SST bias. These modeled ocean surface conditions impact on the West African boreal summer monsoon, leading to enhanced continental precipitation and reduced rainfall in the northern Gulf of Guinea. Concomitant subsidence may have enhanced modeled JJA rainfall over the Congo Basin in a Walker-cell type response.

- While our analysis suggests that the model errors in downwelling radiation are more important in JJA than in DJF, they seem to be less important for the warm bias than ocean dynamics when seen over all seasons. However, a definite answer to this question would require a full consideration of atmospheric and ocean heat budgets.

- The specification of the SAA south of the Angola Benguela Front Zone as external forcing improves the simulation of the seasonal cycle in the tropical Atlantic, revealing the fundamental role of this anticyclone in shaping the climatology of the region. This conclusion represents an instance of the utility of regional coupled models and the domain-shifting technique implemented here for the identification of the key contributors to the climate of a given area of interest.

We can conclude that coupled models aiming at reproducing the natural climate variability in this region of the globe should include an adequate representation of the SAA, which in the light of our results demands the nontrivial task of capturing the intricate loop of feedbacks involving the subtropical zonal SST gradient, land-sea heating contrasts, and ocean dynamics. The methodology developed in this paper would allow us to study the impact of the SAA on the interannual variability in the SETA region. In such a study, inter-basin influences, like the atmospheric bridge between the Pacific and Atlantic Oceans described in Alexander et al. (2002), would need to be taken into consideration. The atmospheric bridge paradigm relates SST warming in the tropical Atlantic Ocean to enhanced subsidence and reduced cloudiness as a consequence of warmer eastern Pacific waters. On the other hand, Atlantic Niños seem to enhance Pacific Niño events in recent decades (Rodríguez-Fonseca et al. 2009; Ding et al. 2012). Future work should therefore also analyze in detail the interaction of the northern and southern hemispheric subtropical anticyclones in the Atlantic Ocean with both the Atlantic and Pacific Hadley and Walker cell systems.

Acknowledgments We would like to thank Professor Roberto Mechoso for valuable comments, suggestions and discussions that helped to improve the paper. We thank the three referees for the constructive suggestions, which helped to improve the manuscript. The model simulations were performed at the German Climate Computing Center (DKRZ). We thank ECMWF (http://www.ecmwf.int) for providing ERA-40 reanalysis data. William Cabos was supported by the Peruvian National Fund for Scientific and Technological Development under the project CRYOPER (Grant 7186-2015). Dmitry V. Sein was supported by the German Federal Ministry of Education and 
Research (BMBF) under the project SPACES-AGULHAS (research Grant 03G0835B) and by EC project PRIMAVERA under the Grant Agreement No. 641727. Andreas H. Fink was supported by the DACCIWA project, funded from the European Union Seventh Framework Programme (FP7/2007-2013) under Grant Agreement No. 603502. N. Keenlyside was supported by the PREFACE project, funded from the European Union Seventh Framework Programme (FP7/2007-2013) under Grant Agreement No. 603521.

Open Access This article is distributed under the terms of the Creative Commons Attribution 4.0 International License (http://creativecommons.org/licenses/by/4.0/), which permits unrestricted use, distribution, and reproduction in any medium, provided you give appropriate credit to the original author(s) and the source, provide a link to the Creative Commons license, and indicate if changes were made.

\section{References}

Alexander MA, Bladé I, Newman M, Lanzante JR, Lau N-C, Scott JD (2002) The atmospheric bridge: the influence of ENSO teleconnections on air-sea interaction over the global oceans. J Clim 15:2205-2231

Behringer DW, Xue Y (2004) Evaluation of the global ocean data assimilation system at NCEP: the Pacific Ocean. Eighth symposium on integrated observing and assimilation systems for atmosphere, oceans, and land surface, AMS 84th annual meeting, Washington State Convention and Trade Center, Seattle, Washington, pp 11-15

Brandt P, Caniaux G, Bourles B, Lazar A, Dengler M, Funk A, Hormann V, Giordani H, Marin F (2011) Equatorial upper-ocean dynamics and their interaction with the West African monsoon. Atmos Sci Lett 12:24-30. doi:10.1002/asl.287

Burls NJ, Reason CJC, Penven P, Philander SG (2011) Similarities between the tropical Atlantic seasonal cycle and ENSO: an energetics perspective. J Geophys Res 116:C11010. doi:10.1029/201 1JC007164

Colberg F, Reason CJC (2006) A model study of the Angola Benguela Frontal Zone: sensitivity to atmospheric forcing. Geophys Res Lett 33:L19608. doi:10.1029/2006GL027463

Davies HC (1983) Limitations of some common lateral boundary schemes used in regional NWP models. Mon Weather Rev 111:1002-1012

Ding H, Keenlyside NS, Latif M (2009) Seasonal cycle in the upper equatorial Atlantic Ocean. J Geophys Res 114:C09016. doi:10.1 029/2009JC005418

Ding H, Keenlyside N, Latif M (2012) Impact of the equatorial Atlantic on the El Niño southern oscillation. Clim Dyn 38(9):1965-1972

Ding H, Greatbatch RJ, Latif M, Park W (2015) The impact of sea surface temperature bias on equatorial Atlantic interannual variability in partially coupled model experiments. Geophys Res Lett 42:5540-5546. doi:10.1002/2015GL064799

Doi T, Tozuka T, Yamagata T (2010) The Atlantic meridional mode and its coupled variability with the guinea dome. J Clim 23(2):455-475

Doi T, Vecchi GA, Rosati AJ, Delworth TL (2012) Biases in the Atlantic ITCZ in seasonal-interannual variations for a coarseand a high-resolution coupled climate model. J Clim 25:54945511. doi:10.1175/JCLI-D-11-00360.1

Döscher R, Willen U, Jones C, Rutgersson A, Meier HEM, Hansson U, Graham LP (2002) The development of the regional coupled ocean-atmosphere model RCAO. Boreal Environ Res 7:183-192
Foltz GR, McPhaden MJ (2006) The role of oceanic heat advection in the evolutions of tropical north and south Atlantic SST anomalies. J Clim 19:6122-6138

Harlaß J, Latif M, Park W (2015) Improving climate model simulation of tropical Atlantic sea surface temperature: the importance of enhanced vertical atmosphere model resolution. Geophys Res Lett 42:2401-2408. doi:10.1002/2015GL063310

Hazeleger W, Haarsma RJ (2005) Sensitivity of tropical Atlantic climate to mixing in a coupled ocean-atmosphere model. Clim Dyn 25:387-399

Huang B, Hu Z-Z, Jha B (2007) Evolution of model systematic errors in the tropical Atlantic basin from coupled climate hindcasts. Clim Dyn 28:661-682

Ji X, Neelin JD, Lee S-K, Mechoso CR (2014) Interhemispheric teleconnections from tropical heat sources in intermediate and simple models. J Clim 27:684-697

Joyce TM, Frankignoul C, Yang J, Phillips HE (2004) Ocean response and feedback to the SST dipole in the tropical Atlantic. J Phys Oceanogr 34:2525-2540

Kalnay E et al (1996) The NCEP/NCAR 40-year reanalysis project. Bull Am Meteorol Soc 77:437-471

Kushnir Y, Robinson WA, Chang P, Robertson AW (2006) The physical basis for predicting Atlantic sector seasonal-to-interannual climate variability. J Clim 19:5949-5970

Lass HU, Schmidt M, Mohrholz V, Nausch G (2000) Hydrographic and current measurements in the area of the Angola-Benguela front. J Phys Oceanogr 30:2589-2609

Lee S-K, Mechoso CR, Wang C, Neelin JD (2013) Interhemispheric influence of the northern summer monsoons on southern subtropical anticyclones. J Clim 26:10193-10204

Li G, Xie S-P (2012) Origins of tropical-wide SST biases in CMIP multi-model ensembles. Geophys Res Lett 39:L22703. doi:10.1 029/2012GL053777

Liu H, Grodsky SA, Carton JA (2009) Observed sub-seasonal variability of oceanic barrier and compensated layers. J Clim 22:6104-6119

Lübbecke JF, Böning CW, Keenlyside NS, Xie S-P (2010) On the connection between Benguela and equatorial Atlantic Niños and the role of the South Atlantic Anticyclone. J Geophys Res 115:C09015. doi:10.1029/2009JC005964

Ma C-C, Mechoso CR, Robertson AW, Arakawa A (1996) Peruvian stratus clouds and the tropical Pacific circulation: a coupled ocean-atmosphere GCM study. J Clim 9:1635-1645

Mechoso CR, Robertson AW, Barth N, Davey MK, Delecluse P, Gent PR, Ineson S, Kirtman B, Latif M, Le Treut H, Nagai T, Neelin JD, Philander SGH, Polcher J, Schopf PS, Stockdale T, Suarez MJ, Terray L, Thual O, Tribbia JJ (1995) The seasonal cycle over the tropical Pacific in general circulation models. Mon Weather Rev 123:2825-2838

Meehl GA, Covey C, Taylor KE, Delworth T, Stouffer RJ, Latif M, McAvaney B, Mitchell JFB (2007) The WCRP CMIP3 multimodel dataset: a new era in climate change research. Bull Am Meteorol Soc 88:1383-1394

Mikolajewicz U, Sein D, Jacob D, Kahl T, Podzun R, Semmler $T$ (2005) Simulating Arctic sea ice variability with a coupled regional atmosphere-ocean-sea ice model. Meteorol Z 14(6):793-800

Miyasaka T, Nakamura H (2010) Structure and mechanisms of the Southern Hemisphere summertime subtropical anticyclones. J Clim 23:2115-2130

Müller R, Pfeifroth U, Träger-Chatterjee C, Trentmann J, Cremer R (2015) Digging the METEOSAT treasure-3 decades of solar surface radiation. Remote Sens 7(6):8067-8101

Okumura Y, Xie S-P (2006) Some overlooked features of tropical Atlantic climate leading to a new Niño-like phenomenon. J Clim 19:5859-5874 
Patricola CM, Li M, Xu Z, Chang P, Saravanan R, Hsieh J-S (2012) An investigation of tropical Atlantic bias in a high-resolution coupled regional climate model. Clim Dyn 39:2443-2463

Philander SG, Yoon J-H (1982) Eastern boundary currents and coastal upwelling. J Phys Oceanogr 12(8):862-879

Ratnam JV, Giorgi F, Kaginalkar A, Cozzini S (2008) Simulation of the Indian monsoon using the RegCM3-ROMS regional coupled model. Clim Dyn 33:119-139

Reynolds RW, Smith TM, Liu C, Chelton DB, Casey KS, Schlax MG (2007) Daily high-resolution-blended analyses for sea surface temperature. J Clim 20:5473-5496

Richter I (2015) Climate model biases in the eastern tropical oceans: causes, impacts and ways forward. WIRE Clim Change 6:345358. doi:10.1002/wcc.338

Richter I, Xie S-P (2008) On the origin of equatorial Atlantic biases in coupled general circulation models. Clim Dyn 31:587-598

Richter I, Mechoso CR, Robertson AW (2008) What determines the position and intensity of the South Atlantic anticyclone in austral winter?-An AGCM study. J Clim 21:214-229

Richter I, Xie S-P, Behera S, Doi T, Masumoto Y (2012a) Equatorial Atlantic variability and its relation to mean state biases in CMIP5. Clim Dyn 42:171-188. doi:10.1007/s00382-012-1624-5

Richter I, Xie S-P, Wittenberg AT, Masumoto Y (2012b) Tropical Atlantic biases and their relation to surface wind stress and terrestrial precipitation. Clim Dyn 38:985-1001. doi:10.1007/ s00382-011-1038-9

Rodríguez-Fonseca B, Polo I, García-Serrano J, Losada T, Mohino E, Mechoso CR, Kucharski F (2009) Are Atlantic Niños enhancing Pacific ENSO events in recent decades? Geophys Res Lett 36:L20705. doi:10.1029/2009GL040048

Rodwell MJ, Hoskins BJ (2001) Subtropical anticyclones and summer monsoons. J Clim 14:3192-3211

Saha S et al (2010) The NCEP climate forecast system reanalysis. Bull Am Meteorol Soc 91:1015-1057

Seager R, Kushnir Y, Chang P, Naik N, Miller J, Hazeleger W (2001) Looking for the role of the ocean in tropical Atlantic decadal climate variability.J. Climate 14:638-655

Seager R, Murtugudde R, Naik N, Clement A, Gordon N, Miller J (2003) Air-sea interaction and the seasonal cycle of the subtropical anticyclones. J Clim 16:1948-1966
Sein DV, Koldunov NV, Pinto JG, Cabos W (2014) Sensitivity of simulated regional Arctic climate to the choice of coupled model domain. Tellus A 66:23966. doi:10.3402/tellusa.v66.23966

Sein DV, Mikolajewicz U, Gröger M, Fast I, Cabos W, Pinto JG, Hagemann S, Semmler T, Izquierdo A, Jacob D (2015) Regionally coupled atmosphere-ocean-sea ice-marine biogeochemistry model ROM: 1. Description and validation. J Adv Model Earth Syst 7:268-304. doi:10.1002/2014MS000357

Seo H, Jochum M, Murtugudde R, Miller AJ (2006) Effect of ocean mesoscale variability on the mean state of tropical Atlantic climate. Geophys Res Lett. doi:10.1029/2005GL025651

Steele M, Morley R, Ermold W (2001) PHC: a global ocean hydrography with a high-quality Arctic Ocean. J Clim 14:2079-2087

Tanimoto Y, Xie S-P (2002) Inter-hemispheric decadal variations in SST, surface wind, heat flux and cloud cover over the Atlantic Ocean. J Meteorol Soc Jpn 80:1199-1219

Taylor KE, Stouffer RJ, Meehl GA (2012) An overview of CMIP5 and the experiment design. Bull Am Meteorol Soc 93:485-498. doi:10.1175/BAMS-D-11-00094.1

Uppala SM et al (2005) The ERA-40 re-analysis. Q J R Meteorol Soc 131:2961-3012. doi:10.1256/qj.04.176

Vizy EK, Cook KH (2013) Capturing the Atlantic cold tongue and coastal upwelling in an intermediate-level ocean model coupled to a regional climate model. Clim Dyn. doi:10.1007/ s00382-013-1807-8

Wahl S, Latif M, Park W, Keenlyside N (2011) On the tropical Atlantic SST warm bias in the Kiel climate model. Clim Dyn 36:891906. doi:10.1007/s00382-009-0690-9

Weingartner TJ, Weisberg RH (1991) On the annual cycle of equatorial upwelling in the central Atlantic Ocean. J Phys Oceanogr 21:68-82

Xu Z, Li M, Patricola C, Chang P (2014) Oceanic origin of southeast tropical Atlantic biases. Clim Dyn 43:2915-2930 